\title{
Thermomechanical Fatigue Behaviour of Aged Heat Resistant Austenitic Alloys
}

Hugo Wärner, Mattias Calmunger, Guocai Chai, Sten J ohansson and J ohan Moverare

The self-archived postprint version of this journal article is available at Linköping University Institutional Repository (DiVA):

http:/ / urn.kb.se/ resolve?urn=urn:nbn:se:liu:diva-159644

N.B.: When citing this work, cite the original publication.

Wärner, H., Calmunger, M., Chai, G., J ohansson, S., Moverare, J ., (2019), Thermomechanical Fatigue Behaviour of Aged Heat Resistant Austenitic Alloys, International J ournal of Fatigue, (127), 509-521. https:/ / doi.org/ 10.1016/j.ijfatigue.2019.06.012

Original publication available at:

https:// doi.org/ 10.1016/j.ijfatigue.2019.06.012

Copyright: Elsevier

http:// www.elsevier.com/

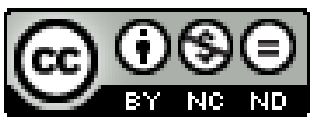




\title{
Thermomechanical fatigue behaviour of aged heat resistant austenitic alloys
}

\author{
Hugo Wärner ${ }^{\mathrm{a}, *}$, Mattias Calmunger ${ }^{\mathrm{a}}$, Guocai Chai ${ }^{\mathrm{a}, \mathrm{b}}$, Sten Johansson ${ }^{\mathrm{a}}$, Johan Moverare ${ }^{\mathrm{a}}$ \\ ${ }^{a}$ Department of Management and Engineering, Linköping University, 58183 Linköping Sweden \\ ${ }^{b} A B$ Sandvik Materials Technology $R$ and D Center, 81181 Sandviken, Sweden
}

\begin{abstract}
The increasing demands for efficiency and flexibility result in more severe operating conditions for the materials used in critical components of biomass power plants. These operating conditions involve higher temperature ranges, more pronounced environmental effects and cyclic operations. Austenitic stainless steels have shown to possess promising high temperature properties which makes them suitable as candidates for critical components in biomass power plant. However, their behaviour under such conditions is not yet fully understood. This work investigates three commercial austenitic alloys: Esshete 1250, Sanicro 25 and Sanicro 31HT. The alloys were subjected to in-phase (IP) thermomechanical fatigue (TMF) testing under strain-control in the temperature range of $100^{\circ} \mathrm{C}$ to $800^{\circ} \mathrm{C}$. Both virgin and pre-aged TMF specimens were tested in order to simulate service degradation resulting from long-term usage. The results show that the pre-aged specimens suffered shorter TMF-life compared to the virgin specimens. The scanning electron microscopy methods electron backscatter diffraction (EBSD) and energy dispersive spectroscopy (EDS) were used to analyse and discuss active failure and deformation mechanisms. The difference in TMF-life produced by the two testing conditions was attributed to an embrittling effect by precipitation, reduced creep properties and oxidation assisted cracking.
\end{abstract}

Keywords: Thermomechanical fatigue, austenitic alloys, pre-ageing

\section{Introduction}

The increase in global energy consumption and the emissions of greenhouse gases (e.g. $\mathrm{CO}_{2}$ ) causing global warming, require a need for more sustainable power generation [1, 2]. This could be accomplished by increasing the efficiency of biomass-fired power plants, and this can be achieved by increasing the temperature and pressure in the boiler sections 3, 4. In addition, a flexible generation of power is critical if only renewable power generation is to be achieved, and this will increase the number of start and stop cycles [5]. The change in operating conditions will increase the demands on the materials in the critical components of the biomass-fired power plants. Cyclic operating condition in a long-term high temperature environment is a process that such materials must withstand, in order to satisfy the needs in future power generation.

Since the lifetime of power plants is expected to be 30 years or more, the materials used for critical components need to have good long-term high temperature performance in order to maintain structural integrity and fulfil safety requirements [4, 6, 7,. Commonly, austenitic stainless steel is used for the critical components of power plants [3, 4, 8. Because of future changes in operating conditions, more investigations are needed to verify that the demands

\footnotetext{
${ }^{*}$ Corresponding author

Email address: hugo.warner@liu.se (Hugo Wärner)
}

on safety and structural integrity for long-term use is fulfilled. One way to investigate the simultaneous change in both mechanical load and temperature of the materials used in new efficient biomass-fired power plants is to study their thermomechanical fatigue (TMF) behaviour 9. InPhase (IP)-TMF (tensile loading is concurrent with heating and maximum strain coincides with maximum temperature) give a good estimation of the boiler component behaviour during start up and shut down operating condition in a power plant 4 .

This study investigates the IP-TMF response for different temperature-loading conditions on three commercial austenitic alloys. In order to analyse the influence of longterm service conditions, both virgin and pre-aged material were studied. Scanning electron microscopy was used to study the deformation and fracture mechanisms.

\section{Experimental procedures}

\subsection{Material - Austenitic alloys}

The investigation involved three commercial austenitic alloys: Sanicro 25 (solution heat-treated at $1220^{\circ} \mathrm{C}$ for 10 minutes), Sanicro $31 \mathrm{HT}$ (solution heat-treated at $1200^{\circ} \mathrm{C}$ for 15 minutes) and Esshete 1250 (solution heat-treated at $1100^{\circ} \mathrm{C}$ for 15 minutes). Sandvik Materials Technology AB have provided and heat-treated the materials. The chemical compositions of the investigated materials in wt.\% are given in Table 1 . 
Table 1: Chemical composition (in wt.\%) of the austenitic alloys.

\begin{tabular}{|c|c|c|c|c|c|c|c|c|c|c|c|c|c|c|c|}
\hline Material & $\mathrm{C}$ & $\mathrm{Cr}$ & $\mathrm{Ni}$ & $\mathrm{W}$ & $\mathrm{Co}$ & $\mathrm{Cu}$ & $\mathrm{Mn}$ & $\mathrm{Nb}$ & $\mathrm{N}$ & $\mathrm{Si}$ & $\mathrm{V}$ & Mo & $\mathrm{Ti}$ & $\mathrm{Al}$ & $\mathrm{Fe}$ \\
\hline Sanicro 25 & 0.1 & 22.5 & 25.0 & 3.6 & 1.5 & 3.0 & 0.5 & 0.5 & 0.23 & 0.2 & - & - & - & - & Bal. \\
\hline Sanicro $31 \mathrm{HT}$ & 0.07 & 20.5 & 30.5 & - & - & - & 0.6 & - & - & 0.6 & - & - & 0.5 & 0.5 & Bal. \\
\hline Esshete 1250 & 0.1 & 15 & 9.5 & - & - & - & 6.3 & 1.0 & - & 0.5 & 0.3 & 1.0 & - & - & Bal. \\
\hline
\end{tabular}

\subsection{Mechanical testing}

The testing procedure employed was strain controlled thermomechanical fatigue (TMF) testing with 5 minutes dwell time at maximum mechanical strain range $\left(\Delta \varepsilon_{\text {mech, max }}\right)$ and maximum temperature. The test machine was a servohydraulic TMF machine from Instron with induction heating and forced air-cooling. Before the TMF tests the machine was carefully aligned, to prevent buckling and other instability effects, according to "the validated code of practice" [10]. This study only includes the In-Phase (IP) cycle with $\mathrm{R}_{\varepsilon}=0$ and in Fig. 1 a simplified plot of the most common TMF test cycles are displayed. The temperature range used was $100^{\circ} \mathrm{C}$ to $800^{\circ} \mathrm{C}$ and the heating and cooling rate was $5^{\circ} \mathrm{C} / \mathrm{s}$. The test specimens were carefully machined from wrought bars according to the schematics in Fig. 2 and some specimens were aged at $800^{\circ} \mathrm{C}$ for 2000 hours before testing and machining in order to simulate microstructural degradation from extended service time. The setup of the tests were done according to [10, with spot welded thermocouples aligned in the longitudinal direction, at a distance of $1 \mathrm{~mm}$ between each other and the strain was measured with a high-temperature extensometer with a gauge length of $12.5 \mathrm{~mm}$. The thermal strain was subtracted from the measured total strain, so that the mechanical strain could be controlled as suggested by [10]. The number of cycles to failure $\left(N_{\mathrm{f}}\right)$ was defined as the point where the maximum stress range $(\Delta \sigma)$ decreases $10 \%$ 10. However, the test was not stopped until a load drop of $60 \%$ occurred. In order to examine the creep effect at the dwell times, a constant mean stress was considered during the relaxation for every test cycle and with the Young's modulus (at $800^{\circ} \mathrm{C}$ ), the strain rate during the dwell time was approximated.

\subsection{Microscopic investigation}

After testing, the specimens were cut, ground and polished following the procedure shown in Table 2. The mi-

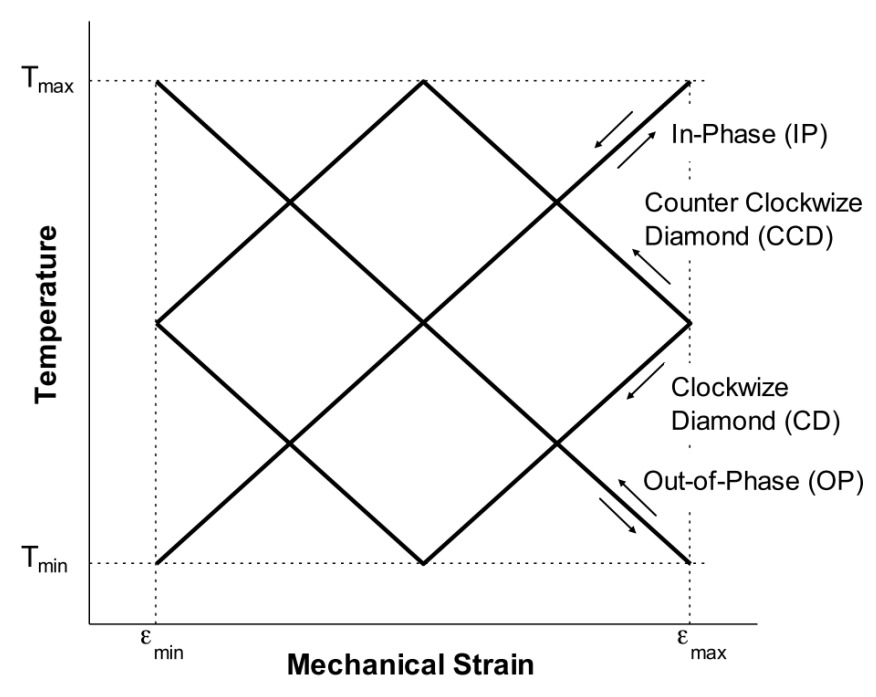

Figure 1: Common TMF test cycles.

crostructural investigations were performed with a HITACHI SU-70 field emission gun (FEG)-SEM equipped with a solid-state backscattered electron (BSE) detector, using $10-20 \mathrm{kV}$ acceleration voltage and working distances between $7 \mathrm{~mm}$ and $18 \mathrm{~mm}$. The different techniques used for analysis were electron backscatter diffraction (EBSD), energy-dispersive spectroscopy (EDS) and wavelength-dispersive spectroscopy (WDS). WDS was mainly used for separating tungsten and silicon peaks. The software Thermo-Calc together with the TCFE9 (Steels and Fe-Alloys) database, were used for equilibrium simulations of the precipitation process for the investigated materials.

Table 2: Steps of the sample preparation.

\begin{tabular}{lccc}
\hline Grinding paper/polishing cloth & Grain size $[\mu]$ & Time $[\mathrm{min}]$ & Number of papers \\
\hline SiC paper, 500 & 30 & 4 & 2 \\
$\mathrm{SiC}$ paper, 1200 & 15 & 4 & 1 \\
$\mathrm{SiC}$ paper, 4000 & 5 & 4 & 3 \\
Silk cloth & Diamond suspension, 3 & 8 & \\
Woven wool cloth & Diamond suspension, 1 & 10 & \\
Rayon-viscose fibres cloth & Diamond suspension, 0.25 & 15 & \\
Neoprene foam cloth & Colloidal silica suspension, 0.04 & 5 & \\
Neoprene foam cloth & water & 1 & \\
\hline
\end{tabular}




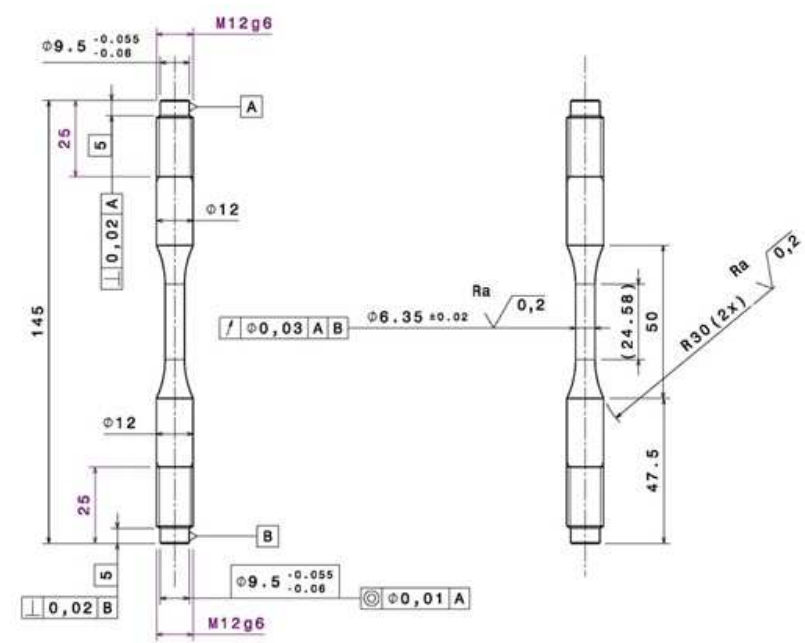

Figure 2: Schematics of the test specimens (units in millimetres).
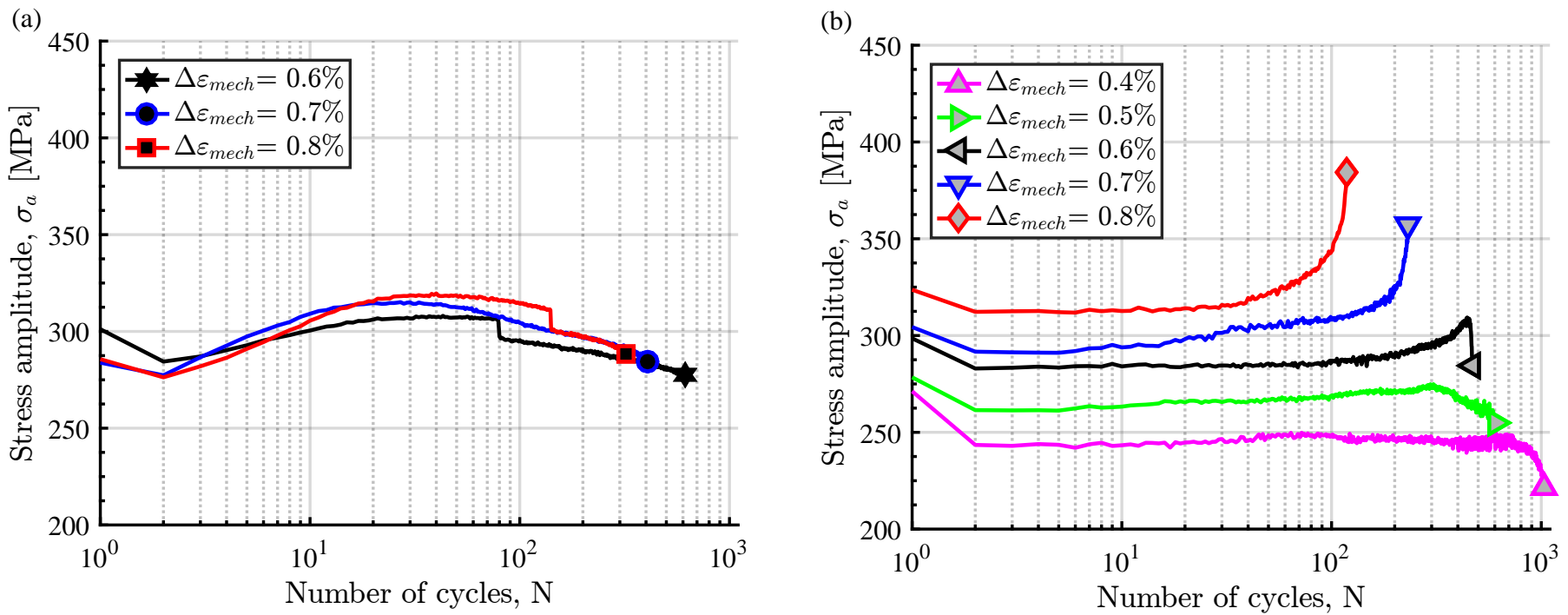

Figure 3: Sanicro 25 cyclic hardening/softening curves. Stress amplitude vs. number of cycles, (a) virgin material, (b) pre-aged material. The test data are also published in [11.

\section{Results}

\subsection{Sanicro 25}

In Fig. 3, the difference in cyclic hardening and softening for the TMF cycled virgin and pre-aged Sanicro 25 can be seen. After the initial 10 cycles, the pre-aged specimens (Fig. 3b) hardened until fracture, while the virgin specimens (Fig. 3a) first hardened but then softened until the load-drop stop-criteria were reached. Another interesting observation in Fig. 3 is the big difference in TMF-life for the pre-aged and virgin specimens, of which the preaged specimens has shorter TMF-life compared to the virgin specimens with corresponding mechanical strain range. The plastic strain amplitude at half-life linearly increases with the mechanical strain range $\left(\Delta \varepsilon_{\text {mech }}\right)$ and are generally higher for the pre-aged specimens. This can be seen in Fig. 4a, where the plastic strain amplitude $\left(\varepsilon_{a_{p}}\right)$ is plotted against number of cycles $(N)$. In Fig. $4 \mathrm{~b}$ it can be seen that the dwell time strain rate $(\dot{\varepsilon})$ for the pre-aged specimens is generally higher compared to the virgin specimens at comparable dwell-time mean stress levels $(\sigma)$.

\subsubsection{Microstructural observations}

In Fig. 5 the microstructure of TMF tested virgin and pre-aged Sanicro 25 , with $\Delta \varepsilon_{\text {mech }}=0.6 \%$, are shown. Given the resolution of the EDS-technique, it was difficult to gain precise quantitative results and identification of the different phases and precipitates, especially for those containing light elements $(\mathrm{C}$ and $\mathrm{N})$. All the quantitative results can be seen in Table. 3. In the TMF tested virgin microstructure, Fig. 5a, the EDS-results indicates that the $\mathrm{Nb}, \mathrm{Cr}$ and N-rich precipitates are Z-phases, in the form of $\mathrm{CrNbN}$ [12, 13. In the as-received condition these 

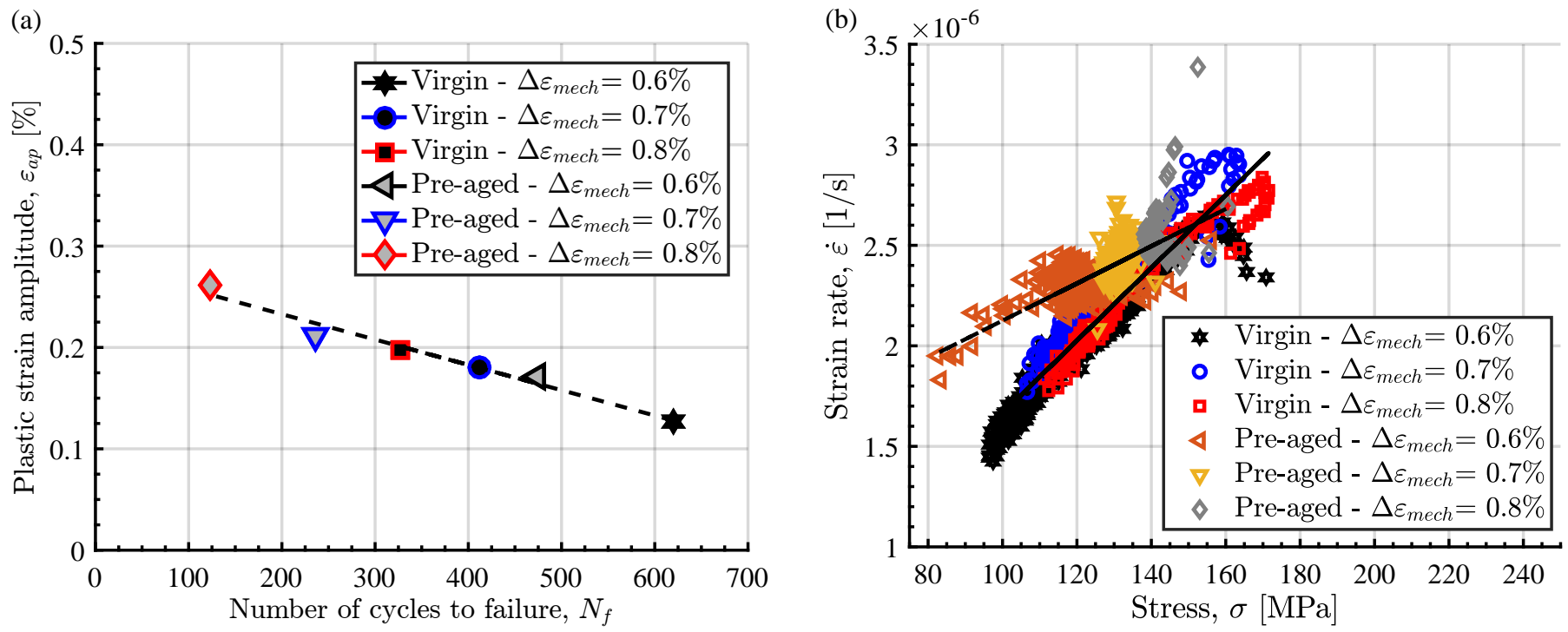

Figure 4: Sanicro 25, (a) Plastic strain amplitude at half-life vs. cycles to failure, (b) strain rate at dwell time vs. mean stress at dwell time.

were the predominant phases [12, 14, 18. The Nb-, Cand N-rich and $\mathrm{Cr}$-decreased precipitates were identified as $\mathrm{Nb}(\mathrm{C}, \mathrm{N})$ in the virgin samples. This is in accordance with [12, 15 18, but in this case the precipitates were coarser. For the more refined precipitates in the matrix and at grain boundaries e.g. type-1, type- 2 and type- 3 sites in Fig. 5, the resolution of the EDS-point technique was poor and precise identification became difficult. However, with the support from literature and Thermo-Calc software calculations [19] the identification process was greatly improved. $\mathrm{Cr}_{2} \mathrm{~N}$ and $\mathrm{M}_{23} \mathrm{C}_{6}$ were identified as the precipitates of the $\mathrm{Cr}-, \mathrm{N}-, \mathrm{C}-$, and $\mathrm{W}$-enriched type- 1 sites [14, 16, 18. The Cr-, C-, and W-enriched type-2 sites, located in the grain boundaries, were identified as $\mu$-phase, represented by $(\mathrm{Cr}, \mathrm{Fe})_{7}(\mathrm{Mo}, \mathrm{W})_{2}(\mathrm{Cr}, \mathrm{Fe}, \mathrm{Mo}, \mathrm{W})_{4}$ and carbides represented by $\mathrm{M}_{23} \mathrm{C}_{6}$ [13, 17. There was a modest increase in chromium at the type-3 sites (grain bounderies between type- 2 precipitates) and given the small size of these areas, this indicated that $\mathrm{M}_{23} \mathrm{C}_{6}$ was present, similar conclusions has been made by 14 16. In addition to the presented EDS-results, investigations by Heczko et al. [15] showed the presence of coherent $\mathrm{Cu}$-rich nanoparticles homogeneously precipitated throughout the austenitic matrix. Findings of tungsten and strain induced $\mathrm{NbC}$ precipitates in solid solution together with the $\mathrm{Cu}$-rich nanoparticles were reported to greatly contribute to the obstruction of dislocation movement [7, 12, 15, 16].

In the TMF tested pre-aged microstructure, Fig. 5b, the EDS-investigations indicated that Z-phases are present, but larger and reduced in numbers, compared with the virgin microstructure. The needle shaped W-rich precipitates inside the grains were identified as Laves phase $(\mathrm{Fe}, \mathrm{Cr})_{2} \mathrm{~W}$ [18, 20]. In contrast to the results from J. Zurek et al. [17, Laves phase was better suited to represent the precipitates in type- 1 sites for the pre-aged microstructure. This co- incided with the finding from Chai et al. 20] and Vujic et al.[18. These precipitates and $\mathrm{M}_{23} \mathrm{C}_{6}$-carbides were also present in the grain boundaries, at type-2 sites shown in Fig. 5b 17, 18, 20. The composition of the type-3 sites were found to be similar to those in the virgin condition, but with an increase of tungsten and chromium. These results indicated conformity with the study by Zurek et al. [17, where Sanicro 25 was aged for 3000 hours at $750^{\circ} \mathrm{C}$ and resulted in a substantial degree of precipitated $\mathrm{M}_{23} \mathrm{C}_{6}$ in the grain boundaries. These precipitates were increased in size compared to those found in type- 1 sites in the virgin microstructure. This was also confirmed by Thermo-Calc simulations and calculations done by Vujic et al. [18.

The characteristic crack propagation for a virgin and a pre-aged specimen can be seen in Fig. 6 and Fig. 8 . In Fig. 6, the specimens were tested with different mechanical strain ranges but resulted in similar TMF-life. However, the difference in crack formation and propagation were notable. In the virgin material, Fig. 6a, cracks initiated from the surface and propagated mostly intergranuarly with a lot of crack branching and side cracks. In addition, closely located crack initiations tend to coalesce in to bigger cracks. In the pre-aged microstructure, Fig. 6b, there were fewer but bigger cracks and they propagated without any branching and with fewer secondary cracks, indicating higher degree of local plasticity compared to the virgin material. In Fig. 8 , both conditions show intergranular cracking and highly deformed grains close to the crack path. The pre-aged microstructure, Fig. 8b, also show high deformation in the interior of the grains. The crack propagation were in both cases oxidation assisted and one example of this is shown in Fig. 7. where the crack tip contains chromium oxides and the area in front of the crack is Cr-depleted. This has also been investigated and reported by Polák et al. 21 24]. 

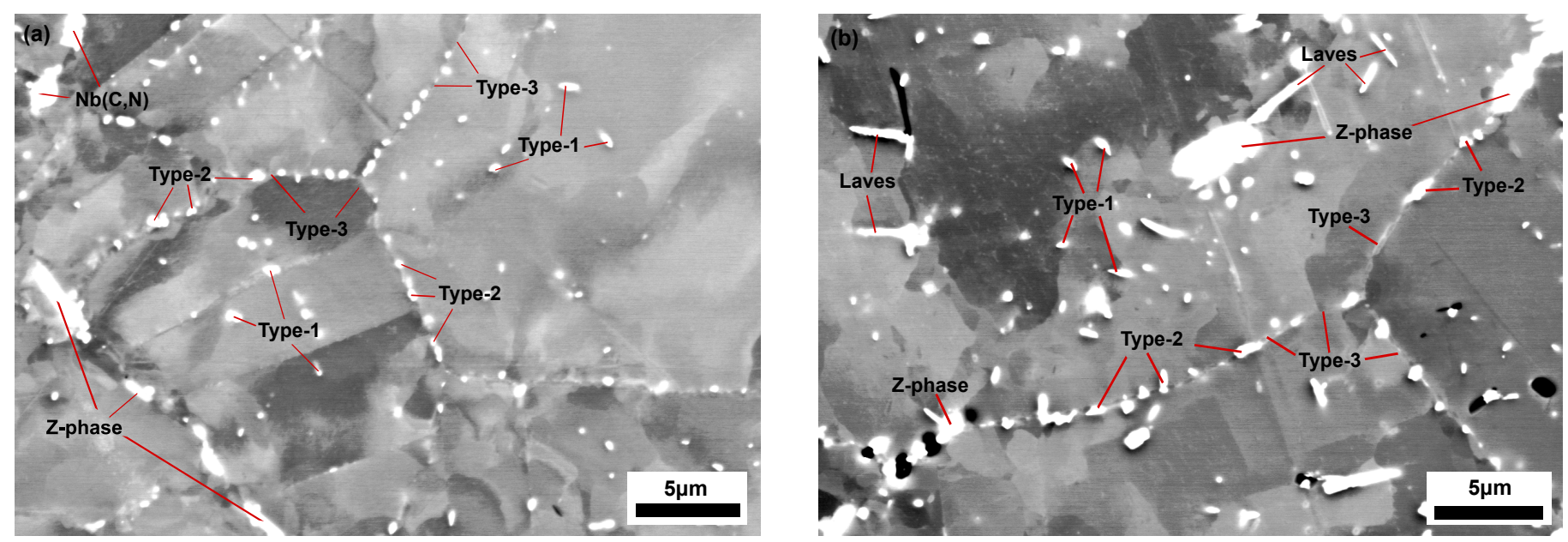

Figure 5: Sanicro 25 microstructure (tested at $\Delta \varepsilon_{\text {mech }}=0.6 \%$ ) (a) virgin specimen, (b) pre-aged specimen.
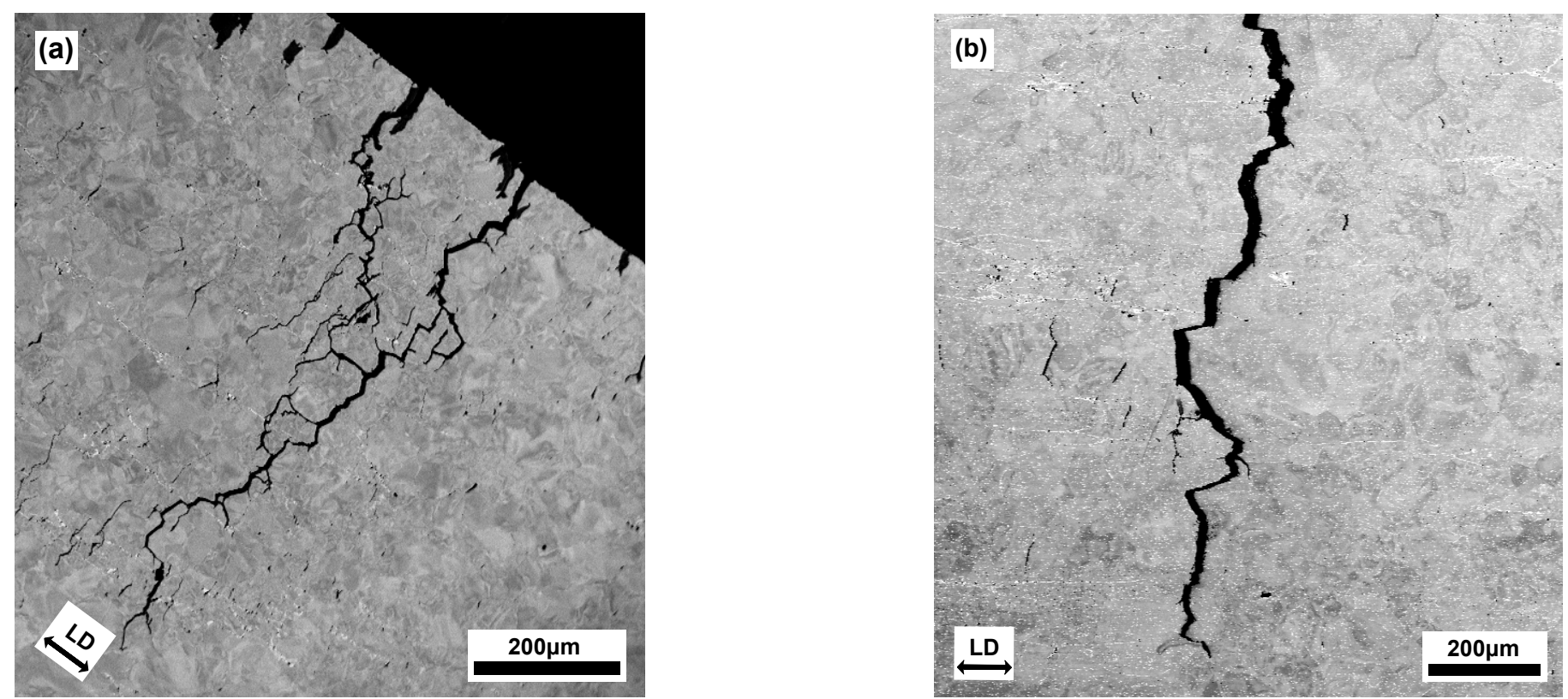

Figure 6: Sanicro 25 main crack overview, (a) virgin specimen $\left(\Delta \varepsilon_{\text {mech }}=0.8 \%, \mathrm{Nf} \approx 400\right.$ cycles $),(\mathrm{b})$ pre-aged specimen $\left(\Delta \varepsilon_{\text {mech }}=0.6 \%, \mathrm{Nf}\right.$ $\approx 450$ cycles)
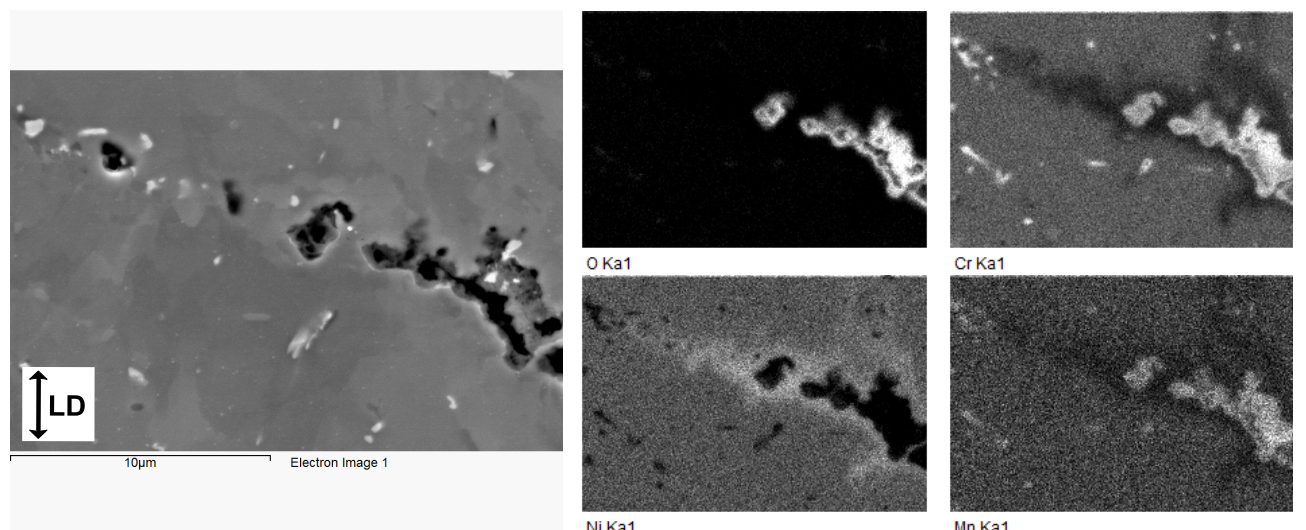

Figure 7: Pre-aged Sanicro $25\left(\Delta \varepsilon_{\text {mech }}=0.6 \%\right)$ crack tip EDS-mapping 
Table 3: Minimum and maximum values (in wt.\%) for the quantitative data of the microstructures in Fig. 5

\begin{tabular}{cccccccc}
\hline Precipitations & $\mathrm{C}$ & $\mathrm{N}$ & $\mathrm{Cr}$ & $\mathrm{Fe}$ & $\mathrm{Ni}$ & $\mathrm{Nb}$ & $\mathrm{W}$ \\
\hline Virgin Sanicro 25 & & & & & & & \\
\hline $\mathrm{Nb}(\mathrm{C}, \mathrm{N})$ & $6.3-8.3$ & $5.2-8.3$ & $13.5-16.8$ & $4.2-5.2$ & $1.3-1.9$ & $45.2-59.0$ & $1.3-1.6$ \\
Z-phase & $3.6-4.8$ & $6.3-7.7$ & $26.5-28.5$ & $6.3-8.5$ & $1.6-2.4$ & $41.8-49.6$ & $2.4-3.8$ \\
$\mathrm{Cr}_{2} \mathrm{~N} / \mathrm{M}_{23} \mathrm{C}_{6}$ (1-type sites) & $2.3-4.9$ & $3.3-4.2$ & $27.9-29.1$ & $23.6-26.9$ & $9.3-14.4$ & $8.5-13.1$ & $4.5-6.0$ \\
$\mu$-phase $/ \mathrm{M}_{23} \mathrm{C}_{6}$ (2-type sites) & $3.8-4.0$ & $0.2-0.3$ & $25.5-27.6$ & $32.4-36.1$ & $17.3-20.7$ & $1.5-1.7$ & $3.4-6.9$ \\
$\mathrm{M}_{23} \mathrm{C}_{6}$ (3-type sites) & $3.4-4.0$ & $0.2-1.0$ & $22.6-27.6$ & $36.1-40.3$ & $21.7-24.3$ & $0.0-0.1$ & $1.5-3.1$ \\
\hline Pre-aged Sanicro 25 & & & & & & & \\
Z-phase & $3.0-3.6$ & $7.3-8.5$ & $24.5-26.4$ & $7.6-8.1$ & $1.4-2.8$ & $44.7-49.0$ & $3.4-6.1$ \\
Laves phase & $2.0-3.1$ & $0.1-0.4$ & $20.4-24.5$ & $28.5-30.6$ & $11.2-14.4$ & $0.2-1.0$ & $35.8-38.2$ \\
Laves phase (1-type sites) & $3.0-4.1$ & $0.1-0.2$ & $18.6-22.7$ & $33.5-37.0$ & $16.0-17.9$ & $0.1-0.2$ & $23.9-26.3$ \\
$\mathrm{M}_{23} \mathrm{C}_{6} /$ Laves phase (2-type sites) & $3.2-3.9$ & $0.2-0.4$ & $19.9-24.7$ & $24.8-29.2$ & $8.9-12.8$ & $0.0-0.2$ & $30.5-40.9$ \\
$\mathrm{M}_{23} \mathrm{C}_{6}$ (3-type sites) & $2.5-3.3$ & $0.0-0.1$ & $26.6-28.8$ & $38.8-41.1$ & $22.4-24.7$ & $0.2-0.3$ & $3.0-3.9$ \\
\hline
\end{tabular}
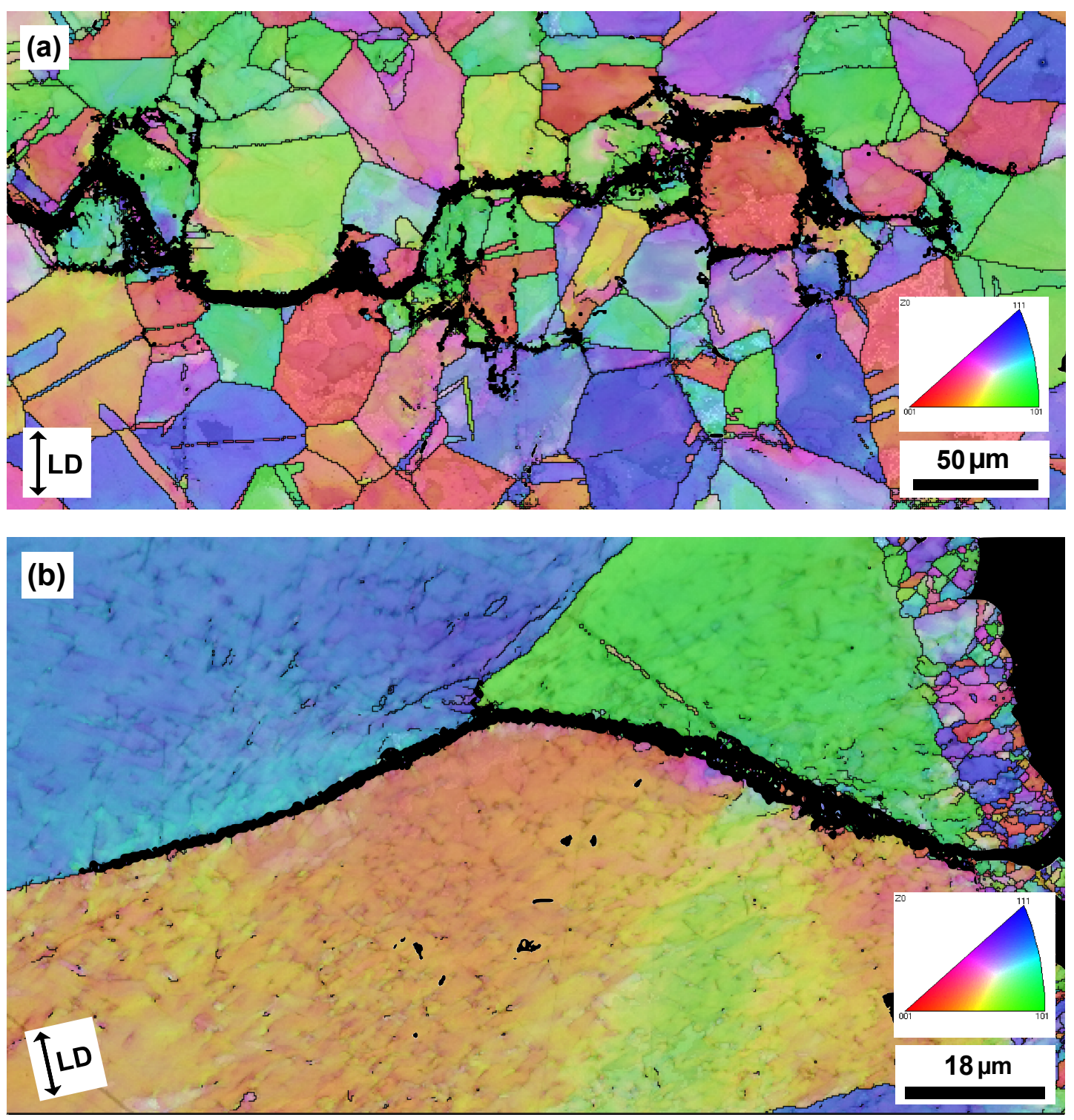

Figure 8: Sanicro 25 crack characteristics (EBSD mapping by IPF colouring with grain boundary contrast), $\Delta \varepsilon_{\text {mech }}=0.8 \%$, (a) virgin specimen, (b) pre-aged specimen. 


\subsection{Sanicro 31HT}

In the case of Sanicro 31HT, the TMF-life were shorter for the pre-aged specimens compared to the virgin specimens, with corresponding test conditions. This can be seen in Fig. 9. In Fig. 9a it can be seen that the virgin Sanicro $31 \mathrm{HT}$ specimens first softened for a few cycles and then hardened until failure or stop due to the stop criteria. In contrast to the virgin Sanicro 25 specimens, the virgin Sanicro 31HT specimens have similar TMF-life for all the different test configurations. As for the pre-aged Sanicro 25 specimens, the pre-aged Sanicro $31 \mathrm{HT}$ specimens experienced hardening until failure or stop, but in contrast to Sanicro 25 the stress levels were lower for the pre-aged specimens compared to the virgin specimens. Fig. 11a indicates that there is a linear relationship between plastic strain amplitude at half-life of the virgin and pre-aged specimens with different TMF-life and mechanical strain ranges. However, the scatter is larger than in the case of Sanicro 25.

During the dwell time the strain rate of the relaxation were higher for the pre-aged specimens compared with the virgin specimens for equal mean stress levels. This can be seen in Fig. 11b. In addition, the virgin specimens experienced relaxation at lower mean stress levels, although the trend is similar for both the virgin and the pre-aged specimens.

\subsubsection{Microstructural observations}

As for Sanicro 25, microstructural investigations were performed for virgin and pre-aged Sanicro 31HT using EDS-analysis, Thermo-Calc software calculations and previous published investigations. Table. 4 includes the EDS quantitative results for the investigated precipitates. In Fig. 10, the BSE images show the locations of the EDSanalysed sites for each testing condition. Both titanium carbides (TiC) and $\mathrm{M}_{23} \mathrm{C}_{6}$ were found in the grain boundaries for the virgin specimen, Fig. 10a. TiC-precipitates were also found inside grains randomly dispersed, generally with a diameter of approximately $1 \mu \mathrm{m}$. These precipitates form during solidification and the intragranular precipitates does not dissolve (can happen for intergranular TiC) during the solution treatment before the TMF testing. From investigations by L.Tan et al. 25, there could also be $(\mathrm{Cr}, \mathrm{Ti})_{2} \mathrm{C}$ precipitates in the FCC matrix, which in this case would have similar appearance as the $\mathrm{TiC}$ in the virgin microstructure. In Fig. 10b, the microstructure of the pre-aged condition is shown. The EDS quantitative results revealed that $\mathrm{M}_{23} \mathrm{C}_{6}$ were present in the grain boundaries. They were substantially larger and fewer than in the virgin microstructure, this have also been observed in other studies [25-27]. At the type-1 sites, small precipitates were found and they were homogenously dispersed throughout the grains. These precipitates were hard to analyse and identify with only the quantitative EDS-results (Table. 4), but the results indicate an increase of chromium and carbon. This has also been observed and
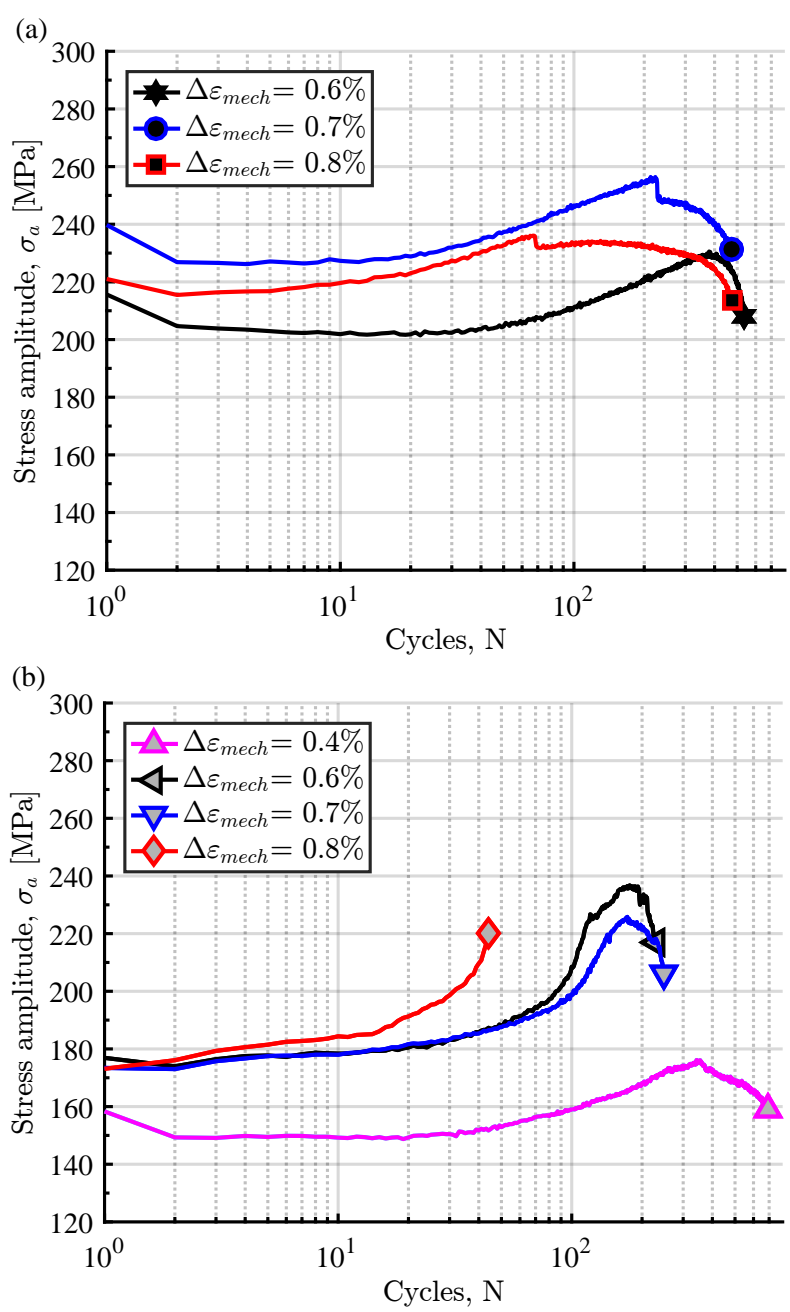

Figure 9: Sanicro 31HT cyclic hardening/softening curves. Stress amplitude vs. number of cycles (a) virgin material, (b) pre-aged material.

denoted as $\mathrm{M}_{23} \mathrm{C}_{6}$ by Khan et al. 27] and Erneman et al. 28. Another alternative identification for these small precipitates could be $\mathrm{Ni}_{3} \mathrm{Ti}$, designated as gamma prime $\left(\gamma^{\prime}\right)$, but according to [28], they should not be present in the microstructure after ageing over approximately $720^{\circ} \mathrm{C}$. The Ti-rich area included $\mathrm{TiC}$ and these precipitates were in general fewer and coarser throughout the pre-aged microstructure compared to the virgin microstructure. One additional observation was that the grain boundaries in Fig. 10b had substantial enrichment of carbon according to the EDS-results.

The crack characteristics for both the virgin and preaged condition can be viewed in Fig. 12. For the virgin condition, the crack propagation was mostly intergranular with a lot of branching and secondary cracks (as seen in the top of Fig. 12a). The secondary cracks and crack branches from the main crack, formed and propagated in the grain boundaries. The crack propagation in the preaged microstructure was both intergranular and transgranular. This can be seen in Fig. 12b. The image also show 
small recrystallized grains close to the crack and at crack tips, probably formed from recrystallization of the plastic zone in front of the crack tips before or after crack propagation. There were few secondary cracks or crack branches as for the virgin microstructure, but the propagation of the crack was intergranular through precipitated grain boundaries. In addition, the average grain size appear to be larger in the pre-aged condition, Fig. $12 \mathrm{~b}$.
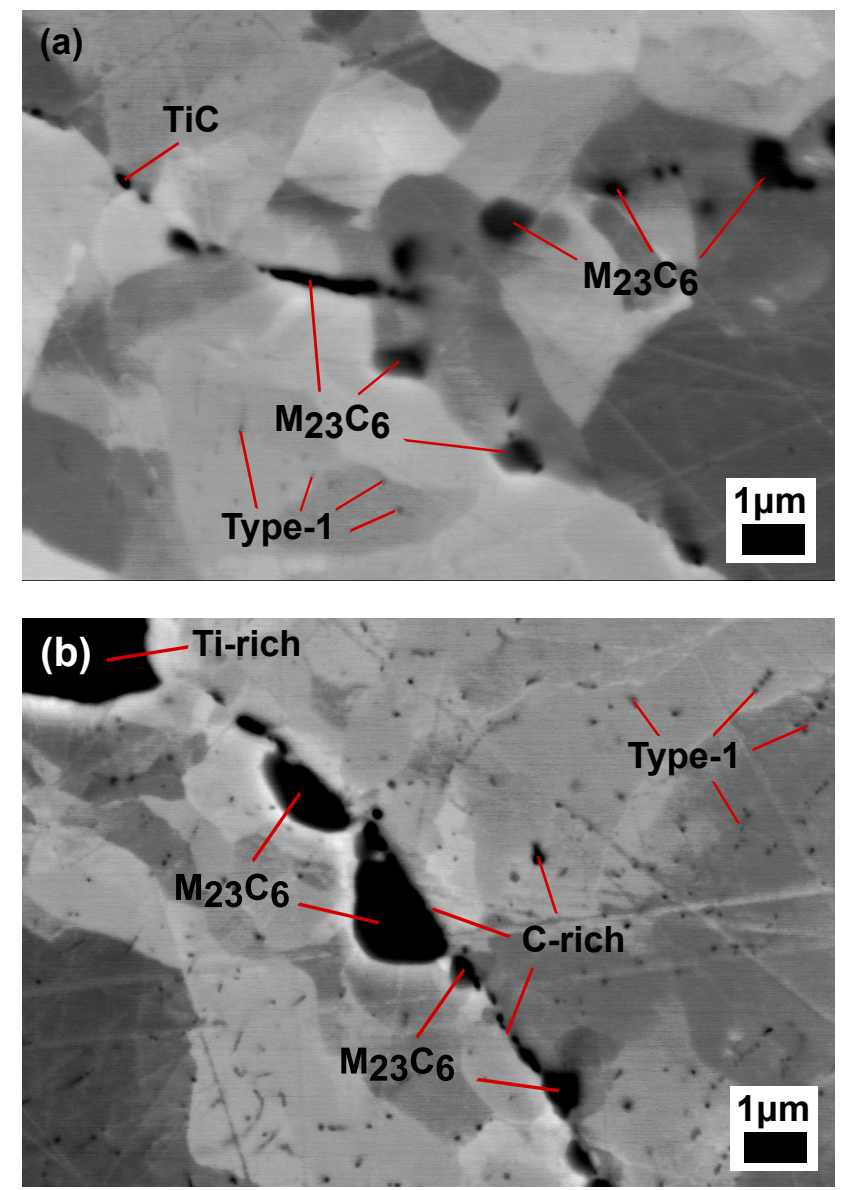

Figure 10: Sanicro 31HT $\left(\Delta \varepsilon_{\text {mech }}=0.7 \%\right)$ microstructure (a) virgin specimen, (b) pre-aged specimen.
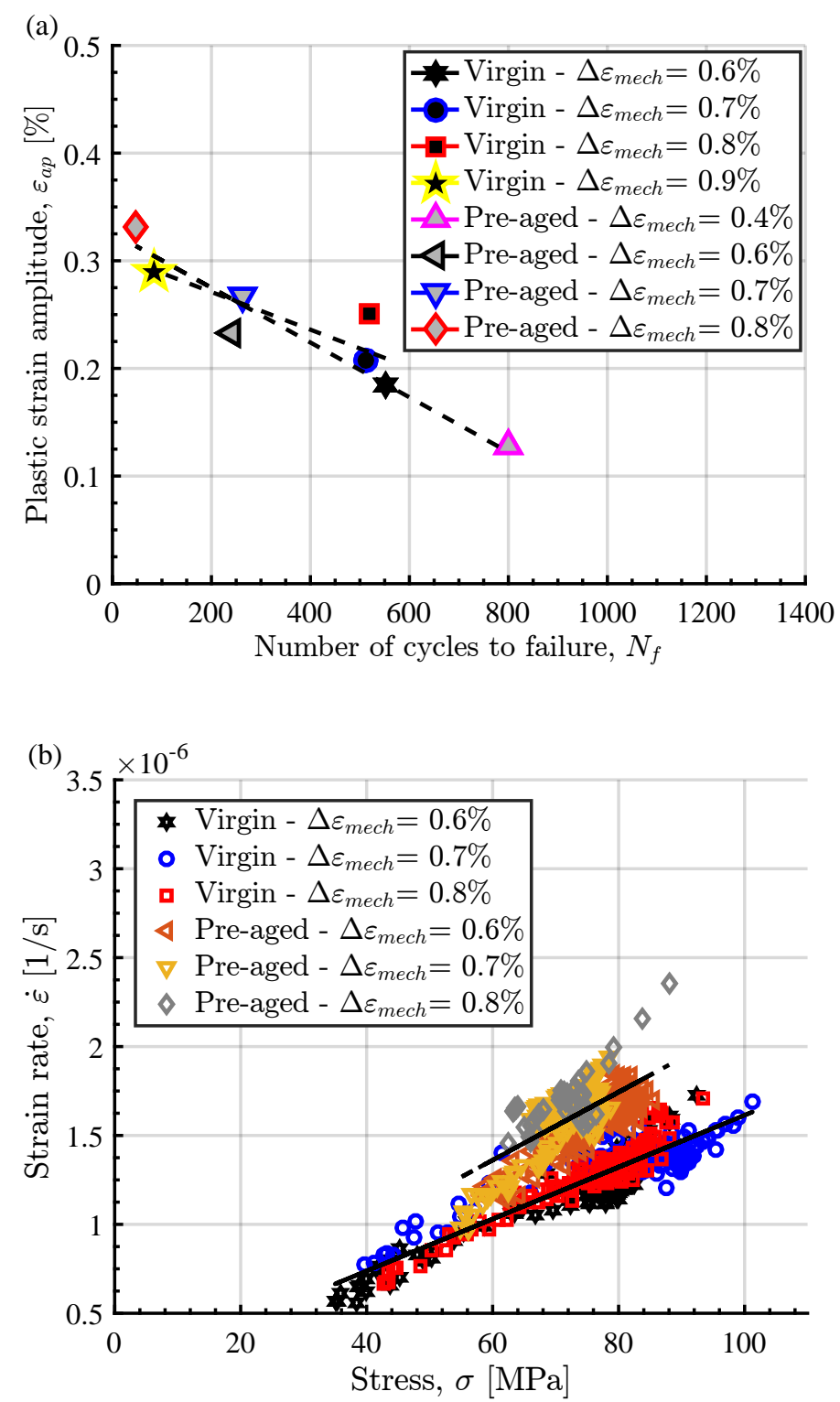

Figure 11: Sanicro 31HT, (a) Plastic strain amplitude at half-life vs. cycles to failure, (b) strain rate at dwell time vs. mean stress at dwell time.

Table 4: Minimum and maximum values (in wt.\%) for the quantitative data of the precipitates in Fig. 10

\begin{tabular}{cccccccc}
\hline Precipitations & $\mathrm{C}$ & $\mathrm{Al}$ & $\mathrm{Si}$ & $\mathrm{Ti}$ & $\mathrm{Cr}$ & $\mathrm{Fe}$ & $\mathrm{Ni}$ \\
\hline Virgin Sanicro 31HT & & & & & & & \\
\hline $\mathrm{TiC}$ & $4.0-7.6$ & $0.0-0.1$ & $0.0-0.1$ & $28.4-30.5$ & $10.8-13.3$ & $38.1-40.6$ & $10.0-10.9$ \\
$\mathrm{M}_{23} \mathrm{C}_{6}$ & $2.8-3.0$ & $0.2-0.3$ & $0.2-0.3$ & $0.4-1.6$ & $35.9-44.1$ & $30.3-31.6$ & $18.4-22.1$ \\
Type-1 sites & $2.7-2.9$ & $0.4-0.5$ & $0.4-0.5$ & $0.3-0.4$ & $20.7-21.3$ & $44.6-45.6$ & $29.2-30.0$ \\
\hline Pre-aged Sanicro 31HT & & & & & & & \\
Ti-enrich & 5.8 & 0.1 & 0.0 & 79.5 & 4.7 & 7.1 & 2.4 \\
$\mathrm{M}_{23} \mathrm{C}_{6}$ & $5.7-6.2$ & 0.1 & 0.1 & 0.5 & $62.2-71.9$ & $9.5-11.5$ & $6.2-11.6$ \\
Type-1 sites & $2.9-3.2$ & $0.4-0.5$ & $0.4-0.5$ & $0.4-0.5$ & $20.5-20.6$ & $44.4-44.7$ & $28.9-29.6$ \\
\hline
\end{tabular}



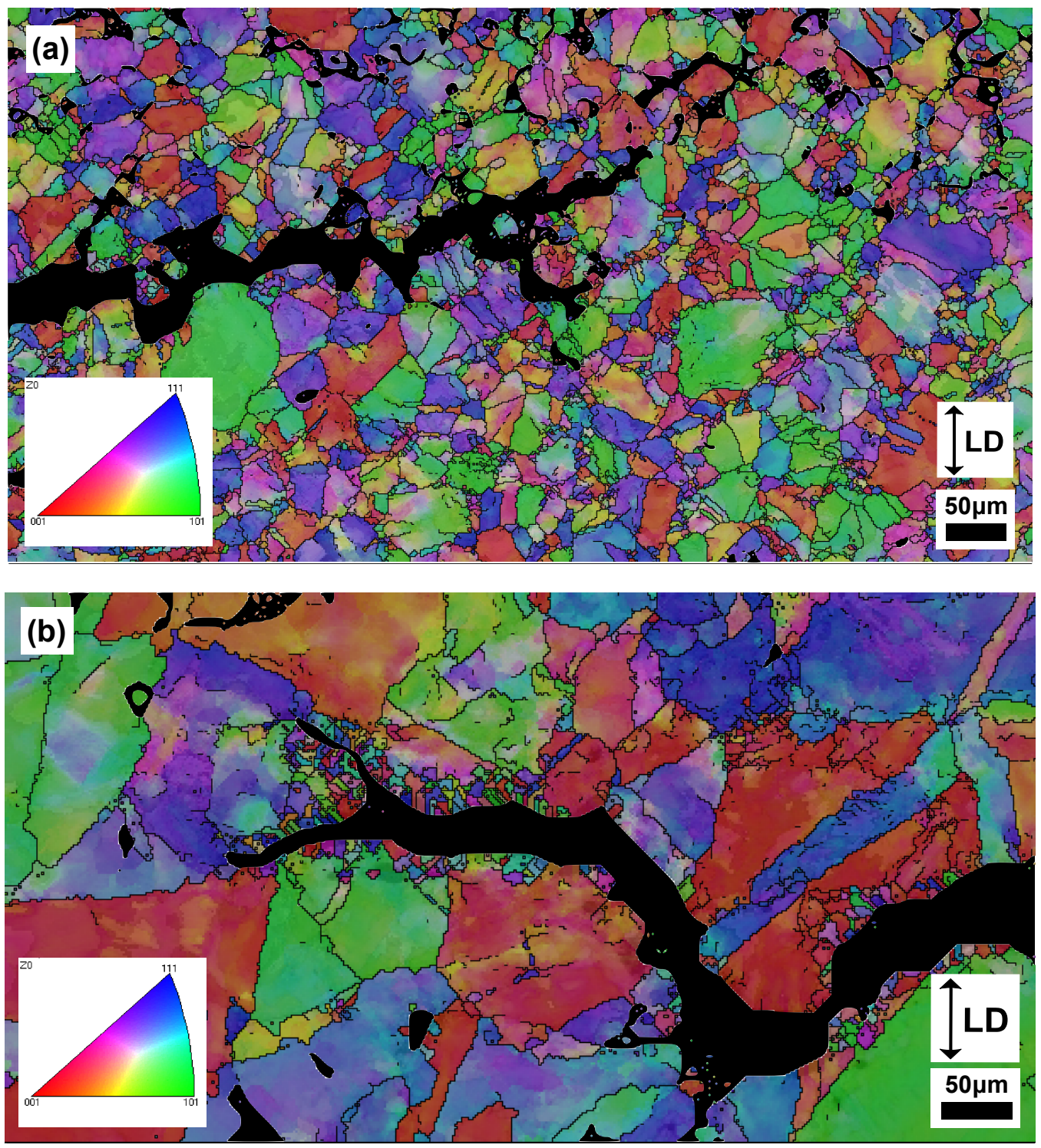

Figure 12: Sanicro $31 \mathrm{HT}$ crack characteristics (EBSD mapping by IPF colouring with grain boundary contrast), $\Delta \varepsilon_{\mathrm{mech}}=0.7 \%,(\mathrm{a}) \mathrm{virgin}$ specimen, (b) pre-aged specimen. 


\subsection{Esshete 1250}

The cyclic hardening/softening curves for Esshete 1250 can be seen in Fig. 13. In Fig. 13a the virgin specimens show hardening until a maximum level was reached after approximately 10 cycles, then they all continuously softened until the failure/stop criteria is reached and the stress equals the levels in the beginning of the tests. The preaged Esshete 1250 TMF testing could only be performed with mechanical strain ranges below $0.5 \%$ in order to get results with data for more than $10 \mathrm{TMF}$-cycles. These results are shown in Fig. 13b and as expected, testing with lower mechanical strain ranges resulted in lower stress levels than for the virgin specimens. Using lower mechanical strain ranges, the influence of pre-ageing yielded longer TMF-life compared the virgin specimens and less plastic strain at half-life (Fig. 14a). In Fig. 14b it can be seen that the strain rate during dwell times were much higher for the pre-aged specimens.

\subsubsection{Microstructural observations}

The general microstructure of Esshete 1250 can be seen in Fig. 15 For the virgin condition, there was a difference in structure close to the specimen surface compared to the middle of the specimen. Close to the surface and at crack tips, Fig. 15a, the crack tip and the following crevices were highly oxidised. This whole area was also mixed with large C- and Nb-rich precipitates at type- 1 sites. In agreement to the findings of Yuin 29, NbC precipitates were found in the as-received state and the precipitates at type- 1 sites were coarse $\mathrm{NbC}$ with increased amount of carbon. In Fig. 15a. enrichment of $\mathrm{Si}$ was also found in an oxidised area. In the middle of the specimen, Fig. 15b, precipitates similar to those at type-1 sites near the surface were found. These were also identified as $\mathrm{NbC}$ with increased carbon content, but slightly reduced in size. In this area, finely dispersed $\mathrm{NbC}$ precipitates were present at type-3 sites inside the grains. Also, Si- and O-rich precipitates identified as $\mathrm{SiO}_{2}$ were discovered. These oxides have a melting point of approximately $1700^{\circ} \mathrm{C}$ and they were probably formed during the manufacturing process of the material [30. Fig. 16 shows the microstructure of the pre-aged condition. Large C- and Nb-rich precipitates identified as carbon rich $\mathrm{NbC}$ precipitates were found at type- 1 sites. In addition to these, finely dispersed $\mathrm{NbC}$ precipitates were found at type- 3 locations and the area at type- 4 sites were enriched in chromium, carbon and molybdenum. As for the virgin condition, the crack fronts of the pre-aged condition were highly oxidised (chromium oxides [31]). No $\mathrm{SiO}_{2}$ inclusions were identified in this area, but there were Si-enriched spots that were usually located in the vicinity of type- 1 sites. In other areas, there were some $\mathrm{SiO}_{2}$ inclusions.

The formation and propagation of cracks for the virgin and pre-aged material can be seen in Fig. 17. The propagation of cracks were generally both transgranular and intergranular, with crack branching. The black areas in front
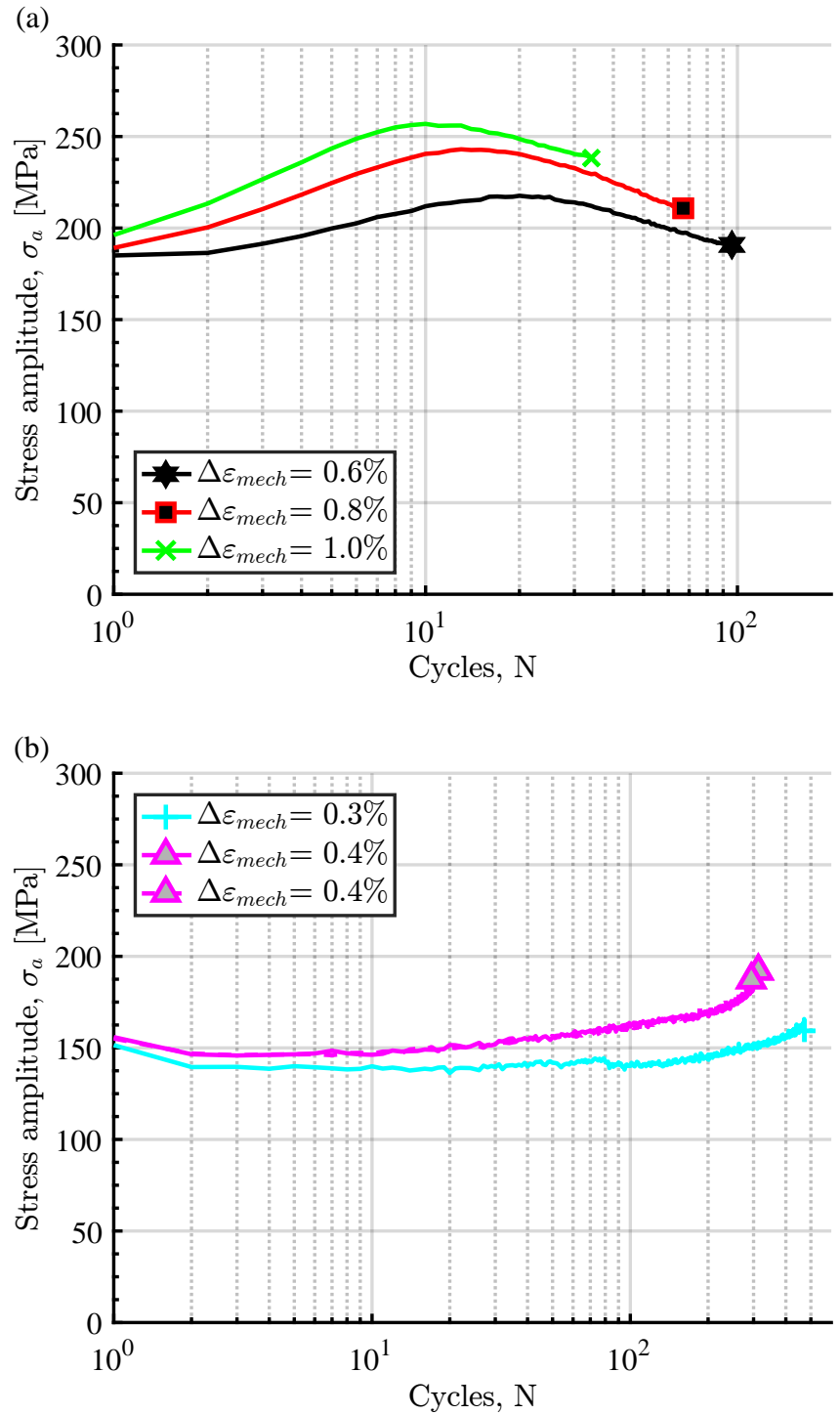

Figure 13: Esshete 1250 hardening/softening curves. Stress amplitude vs. number of cycles, (a) virgin material, (b) pre-aged material.

of the cracks were found to be $\mathrm{SiO}_{2}$ inclusions or cavities where such precipitates were located before the grinding process. The pre-aged microstructure in Fig. $17 \mathrm{~b}$ were in general heavily deformed, which resulted in reduced EBSD indexation quality of the grain boundaries and the FCC structure. However, from the image, it is clear that the crack propagated along the grain boundaries. The areas coloured in black in the microstructure, were identified as $\mathrm{NbC}$ precipitates or $\mathrm{Nb}$-and $\mathrm{C}$-rich precipitates similar to those found at type-1 sites in Fig. 16 . 

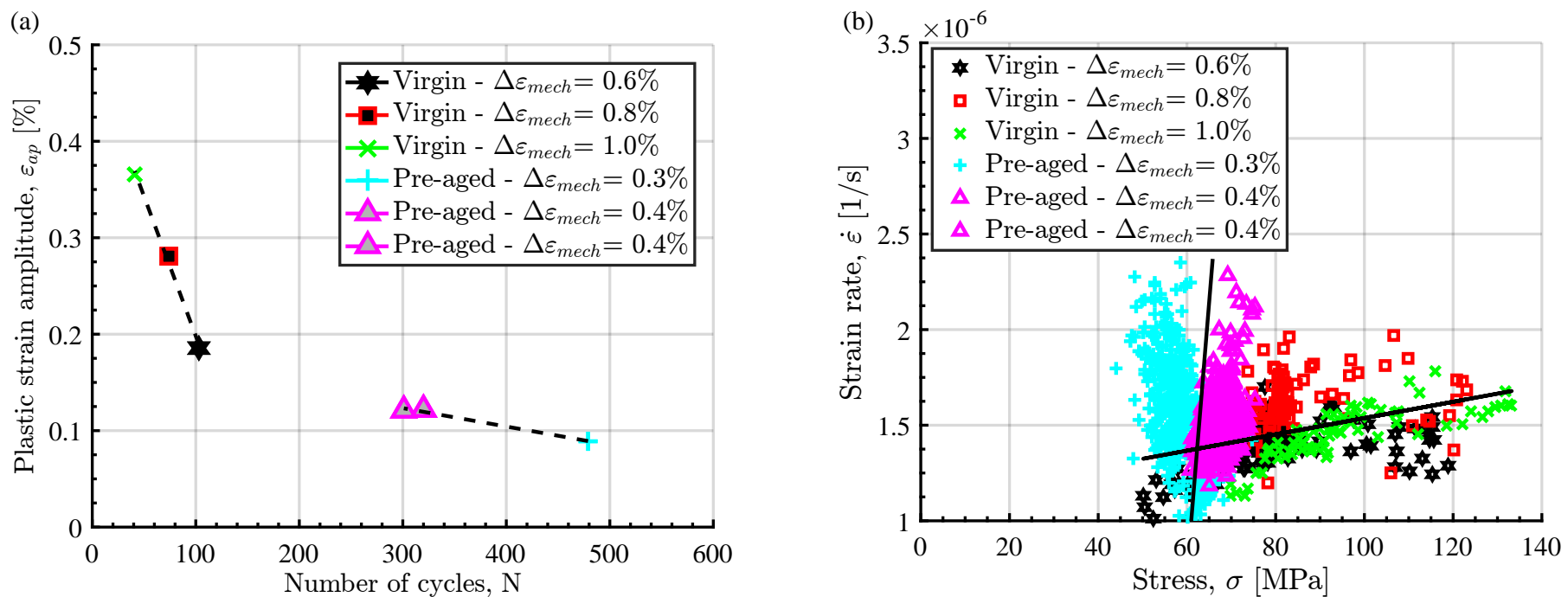

Figure 14: Esshete 1250, (a) plastic strain amplitude at half-life vs. cycles to failure, (b) strain rate at dwell time vs. mean stress at dwell time.
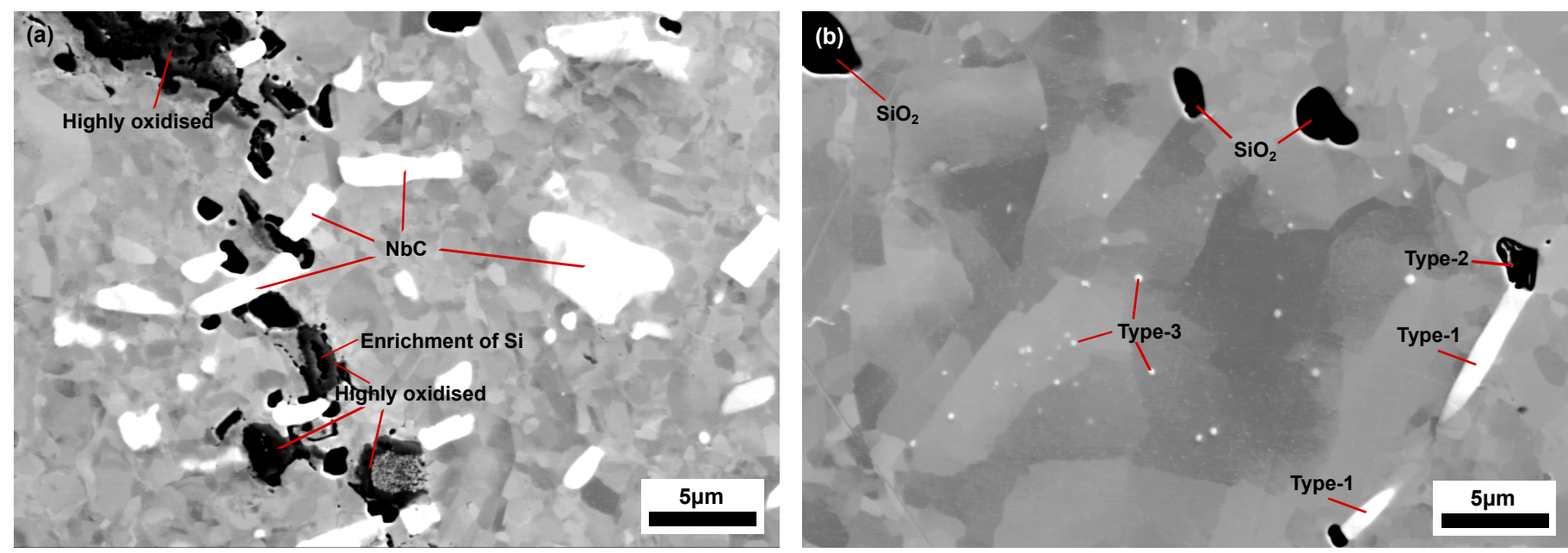

Figure 15: Virgin Esshete $1250\left(\Delta \varepsilon_{\text {mech }}=0.8 \%\right)$ microstructure (a) area close to the specimen surface, (b) area at a distance from the specimen surface.

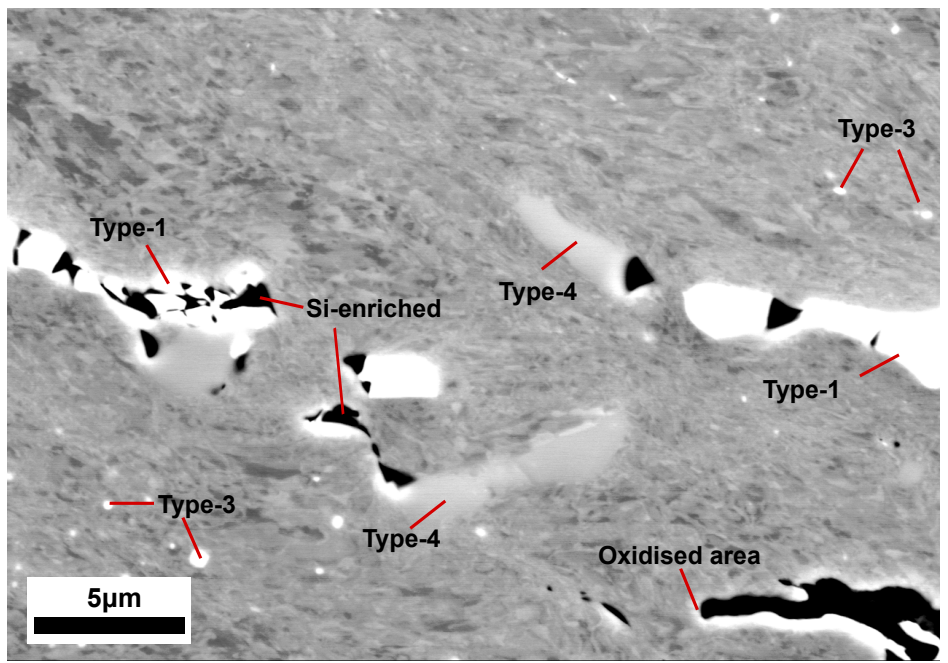

Figure 16: Microstructure of pre-aged Esshete $1250\left(\Delta \varepsilon_{\text {mech }}=0.4 \%\right)$. 
Table 5: Minimum and maximum values (in wt.\%) for the quantitative data of the precipitates in Fig. 15 and Fig. 16

\begin{tabular}{|c|c|c|c|c|c|c|c|c|}
\hline Precipitations & $\mathrm{C}$ & $\mathrm{O}$ & $\mathrm{Si}$ & $\mathrm{Cr}$ & $\mathrm{Mn}$ & $\mathrm{Fe}$ & $\mathrm{Nb}$ & Mo \\
\hline \multicolumn{9}{|l|}{$\begin{array}{l}\text { Virgin Esshete1250 } \\
\text { (close to the surface) }\end{array}$} \\
\hline NbC (Type-1 site) & $16.7-18.6$ & 0.8 & $0.1-0.3$ & $3.0-4.9$ & $1.7-0.7$ & $11.9-19.4$ & $52.9-60.0$ & $0.7-0.8$ \\
\hline Highly oxidised area & $3.6-5.3$ & $25.3-30.4$ & $0.6-0.9$ & $13.3-27.7$ & $4.3-7.3$ & 24.9-30.9 & $1.8-20.7$ & $0.4-0.6$ \\
\hline Si-enrichment area & 4.8 & 11.8 & 1.3 & 9.5 & 2.5 & 55.4 & 3.2 & 1.2 \\
\hline \multicolumn{9}{|l|}{$\begin{array}{l}\text { Virgin Esshete1250 } \\
\text { (In the bulk) }\end{array}$} \\
\hline $\mathrm{SiO}_{2}$ & $3.3-4.1$ & $15.8-23.5$ & $11.1-17.8$ & $9.9-12.2$ & $3.9-5.1$ & $36.3-38.2$ & 0.1 & $0.2-0.3$ \\
\hline NbC (Type-1 sites) & $15.5-16.4$ & 0.7 & 0.1 & $3.4-4.3$ & $0.8-1.2$ & $6.9-10.1$ & $63.8-67.5$ & $0.7-0.8$ \\
\hline C-rich (Type-2 site) & 19.6 & 10.9 & 2.3 & 11.7 & 4.9 & 42.6 & 2.0 & 0.5 \\
\hline NbC (Type-3 sites) & $4.2-5.3$ & $0.3-0.6$ & $0.3-0.4$ & $13.5-15.6$ & $4.0-5.5$ & $49.6-53.9$ & $10.9-12.1$ & $0.5-1.0$ \\
\hline \multicolumn{9}{|l|}{ Pre-aged Esshete1250 } \\
\hline NbC (Type-1 sites) & $13.1-19.3$ & $0.7-1.0$ & $2.3-3.6$ & $1.7-4.0$ & $0.5-0.7$ & $4.1-4.7$ & $68.9-74.0$ & $0.7-1.6$ \\
\hline NbC (Type-3 sites) & $5.0-5.2$ & $0.5-0.6$ & $0.3-0.5$ & $10.6-13.4$ & $3.8-4.0$ & $49.9-51.2$ & $11.0-12.3$ & $0.9-1.6$ \\
\hline (Type-4 site) & 3.7 & 0.8 & 0.9 & 28.7 & 5.8 & 49.7 & 0.0 & 5.8 \\
\hline Oxidised area & 2.9 & 14.0 & 0.9 & 15.5 & 7.5 & 51.1 & 0.1 & 0.7 \\
\hline
\end{tabular}
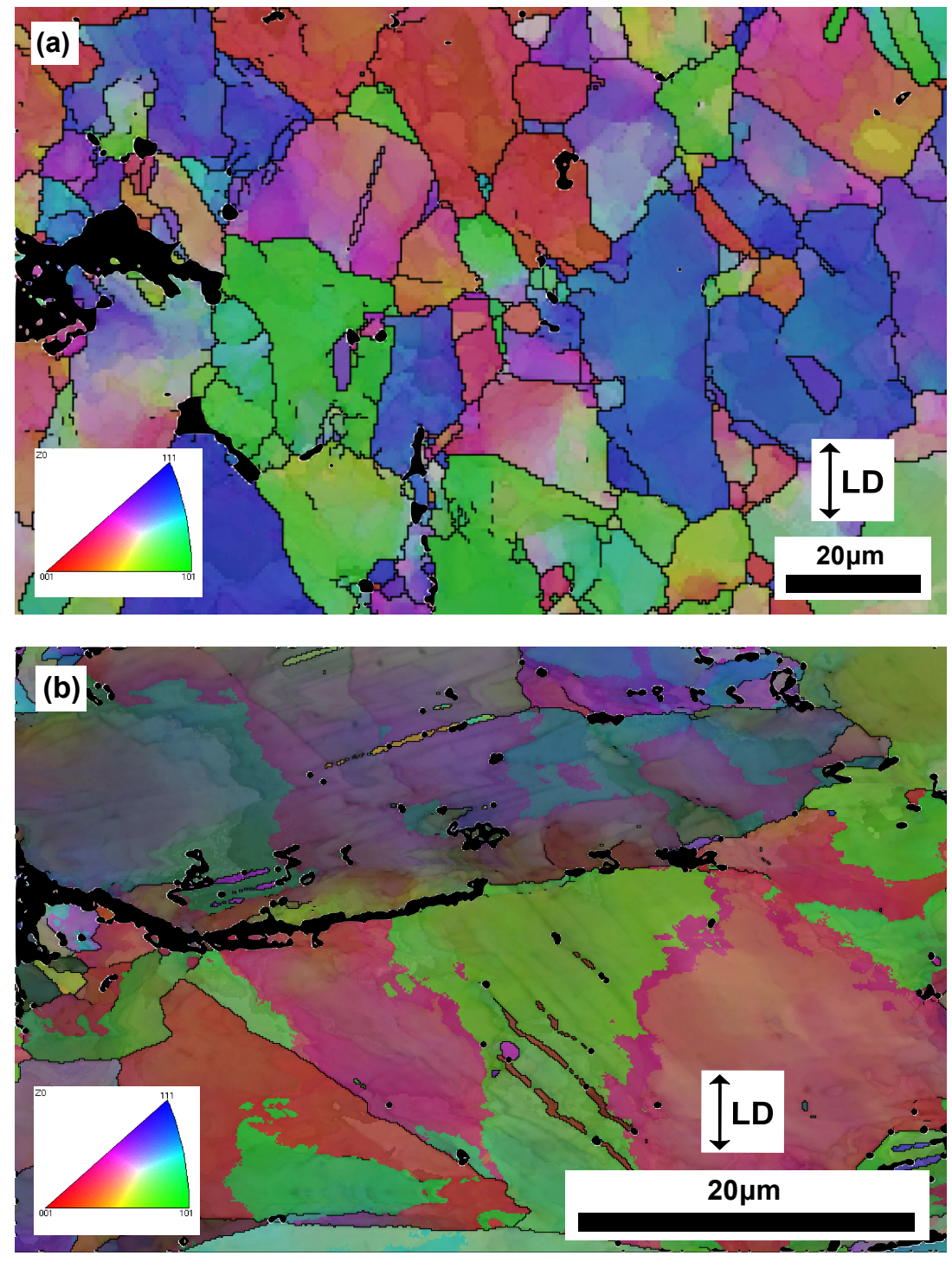

Figure 17: Esshete 1250 crack characteristics (EBSD mapping by IPF colouring with grain boundary contrast), (a) virgin specimen $\left(\Delta \varepsilon_{\text {mech }}=0.6 \%\right),(\mathrm{b})$ pre-aged specimen $\left(\Delta \varepsilon_{\text {mech }}=0.4 \%\right)$ 


\subsection{Fatigue properties}

In Fig. 18 both plastic strain amplitude at half-life vs. number of cycles to fracture (Coffin-Manson curve) and stress amplitude at half-life vs. plastic strain amplitude at half-life (cyclic stress-strain curve, CSSC) are shown. The relationship for the Coffin-Manson curve (Fig. 18a) was approximated by eq. 1 and fitted to experimental data using the least squares procedure.

$$
\varepsilon_{a_{p}}=\varepsilon_{f}^{\prime}\left(2 N_{f}\right)^{c}
$$

The derived parameters, fatigue ductility coefficient $\left(\varepsilon_{f}^{\prime}\right)$ and fatigue ductility exponent $(c)$ are displayed in Table 6. The data from Fig. 18a indicates that, for both Sanicro 25 and Esshete 1250, the virgin specimens generally showed more plastic strain than the pre-aged specimens and had higher values for the fatigue ductility constant and exponent. However, Sanicro 31HT shows a reversed relationship for the trends of the virgin and pre-aged specimens. In addition, for these specimens the fitting was not so good for predicting a reliable trend.

The relationship for the cyclic stress-strain curve (Fig. 18b) was approximated by eq. 2 and fitted to experimental data using the least squares procedure.

$$
\sigma_{a}=K_{f}^{\prime}\left(\varepsilon_{a_{p}}\right)^{n}
$$

The derived parameters, fatigue hardening coefficient $\left(K^{\prime}\right)$ and fatigue hardening exponent $(n)$ can be found in Table 6. The virgin and pre-aged Sanicro 25 in Fig. $18 \mathrm{~b}$ have almost a linear CSSC-response, where the pre-aged specimens are shifted to the right. There is a trend shift (at $\sigma_{a}=295 \mathrm{MPa}$ ) where the pre-aged specimens display lower stress amplitude for corresponding plastic strain amplitude. The Sanicro 31HT data points showed quite large scatter, both for the virgin and pre-aged condition. The virgin specimens showed higher stress amplitudes for corresponding plastic strain amplitudes, but the trend was converging for lower stress amplitudes. Esshete 1250 showed similar CSSC-response as Sanicro 25 but for lower stress amplitudes.

Both the mechanical strain range and the stress amplitude vs. cycles to failure are plotted in Fig. 19. The relationship for the Wöhler curve (Fig. 19b) was approximated by eq. 3 and fitted to experimental data using the least squares procedure.

$$
\sigma_{a}=\sigma_{f}^{\prime}\left(2 N_{f}\right)^{b}
$$

Fig. 19a show a summarising plot of the amount of cycles to fracture in relation to the mechanical strain range. The results in the image provide an overview of the TMFlives for all the investigated materials and testing conditions. It was clear that the Sanicro 25 specimens had the longest TMF-lives, given that the same testing conditions are compared.

The results from the hardness testing, after the TMFcycling, are showed in Fig. 20. According to the curves, the pre-aged Sanicro 25 samples showed the highest overall Vickers hardness values and they increase with increasing applied mechanical strain ranges. The highly deformed pre-aged Esshete 1250 specimens showed very high Vickers hardness for low mechanical strain ranges compared to the other specimens. The Vickers hardness values of Sanicro $31 \mathrm{HT}$ were low and they were not affected much by ageing, but the hardness increased with increasing mechanical strain ranges. The hardness values in the as-received condition were approximately $145 \mathrm{HV}$ for Sanicro 31HT, 175 $\mathrm{HV}$ for Esshete 1250 and $200 \mathrm{HV}$ for Sanicro 25, which does not quite correspond to tabulated values by [8]. The Vickers hardness values were increased after TMF testing for all materials in both conditions.
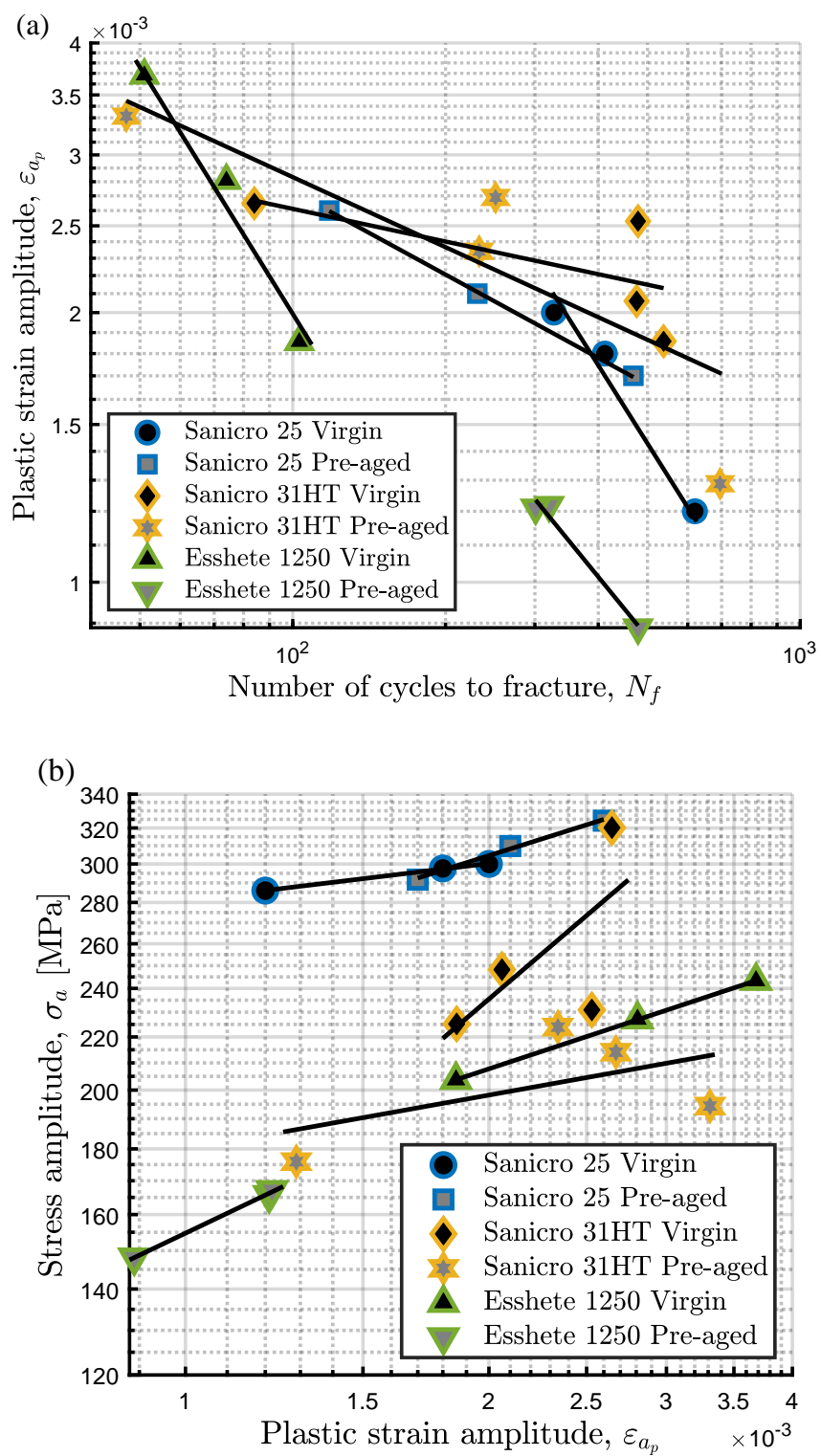

Figure 18: Fatigue curves, (a) Coffin-Manson, (b) Cyclic stress strain curves. Sanicro 25 test data also published in [1]. 

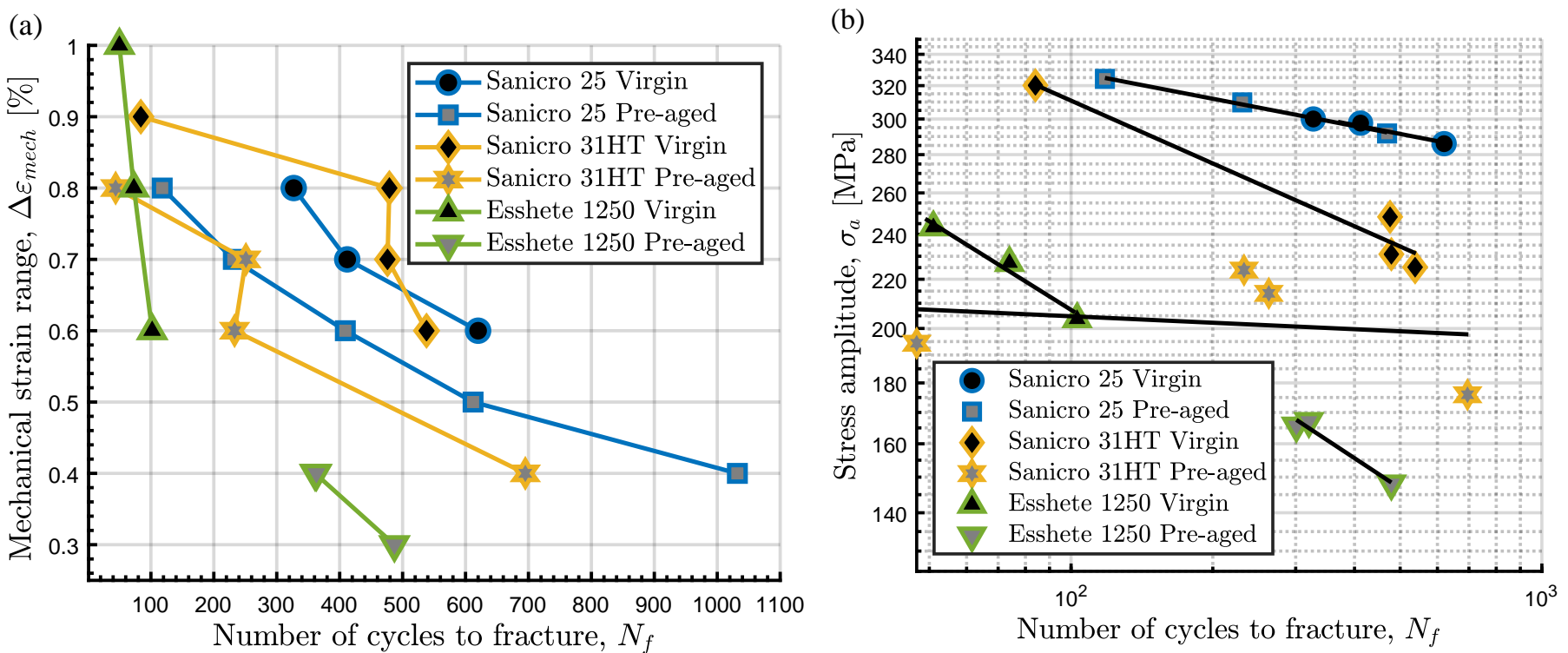

Figure 19: Fatigue life curves, (a) mechanical strain range vs. cycles to failure, (b) Wöhler curves.

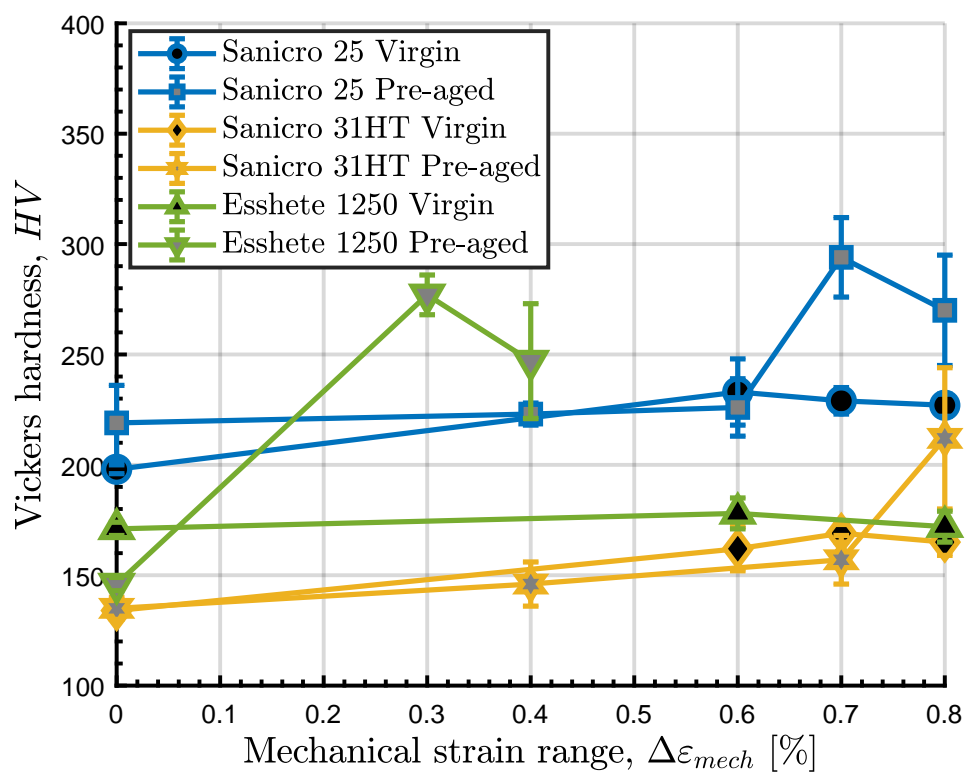

Figure 20: Graph of the Vickers Hardness testing HV5 results vs. mechanical strain range.

Table 6: Parameters of the cyclic stress-strain and TMF-life curves for all investigated materials.

\begin{tabular}{lcccccc}
\hline Material, condition & $\varepsilon_{f}^{\prime}$ & $c$ & $K^{\prime}[\mathrm{MPa}]$ & $n$ & $\sigma_{f}^{\prime}[\mathrm{MPa}]$ & $b$ \\
\hline Sanicro 25, Virgin & 0.716 & -0.9 & 541.0 & 0.0947 & 495.2 & -0.077 \\
Sanicro 25, Pre-aged & 0.014 & -0.309 & 1416 & 0.247 & 492.9 & -0.076 \\
Sanicro 31HT, Virgin & 0.005 & -0.121 & 15220 & 0.671 & 787.2 & -0.175 \\
Sanicro 31HT, Pre-aged & 0.011 & -0.260 & 475.3 & 0.141 & 225.4 & -0.0181 \\
Esshete 1250, Virgin & 0.253 & -0.914 & 1041 & 0.259 & 768.5 & -0.2473 \\
Esshete 1250, Pre-aged & 0.106 & -0.695 & 2057 & 0.375 & 890.7 & -0.261 \\
\hline
\end{tabular}




\section{Discussion}

The investigation of the thermomechanical fatigue properties of three austenitic alloys resulted in different behaviour for the analysed materials, both in mechanical response and microstructural evolution. The investigated materials are designed for evolution of precipitation during high temperature in order to enhance the mechanical properties and consequently the fatigue life [7, 12, 16, 25, 29]. In this study, prolonged service degradation was simulated by TMF testing of pre-aged specimens at corresponding mechanical strain ranges as for the virgin specimens. The investigated materials showed different thermomechanical behaviour, but they all showed a clear deterioration in fatigue response (and fatigue life) for the pre-aged specimens. The extent of this effect on the mechanical properties and the difference between the materials, can be observed when studying Fig. 18, Fig. 19, Table.6 and Fig. 20. From the cyclic stress strain- and Wöhler diagrams, the estimated trend lines seems to indicate that Sanicro 25 have much lower induced plastic strain and more cycles to failure at equivalent stress levels during TMF. The curves also indicate that Sanicro 31HT performs better than Esshete 1250 in this aspect. However, the scatter of the data points for Sanicro 31HT made it hard to fit reliable trend lines, which gives an ambiguous result. The TMF testing also resulted in an estimated Coffin-Manson relationship. Again, the scatter for Sanicro $31 \mathrm{HT}$ made the trend lines less credible. When comparing both conditions for the other two tested materials, the influence of ageing had a more detrimental effect on Esshete 1250 than for Sanicro 25. This corresponds to the difference in TMF-cycle life in Fig. 19b, especially at lower mechanical strain ranges. The reported differences in mechanical response of the investigated materials during TMF are connected to the microstructural evolution during the testing. It is therefore important to analyse this connection in order to be able to understand the TMF behaviour of the investigated materials for both testing conditions.

Sanicro 25 is a relatively high-alloyed austenitic stainless steel and the different alloying elements gives a complex microstructural evolution under high temperature fatigue conditions. In Fig. 3 the difference in fatigue behaviour for the virgin and pre-aged specimens relates to the microstructural evolution difference during testing. This difference in cyclic behaviour is due to a combination of different microstructural deteriorations, giving different fracture behaviour for the two conditions. The pre-aged specimens suffer from an enhanced embrittling effect of the grain boundaries and this is due to the evolution of brittle phases like Laves-phase, Z-phase and excessive precipitation of carbides (mostly $\mathrm{Cr}_{23} \mathrm{C}_{6}$ ) [7, 12. Damage are introduced in the interface surfaces of precipitates and phases in the embrittled grain boundaries, both during the dwell time (due to relaxation) and thermomechanical cycling. These damage initiations in the bulk material can be seen in Fig. 6 and Fig. 8. In addition, the sensitisa- tion of grain boundaries were increased for the pre-aged condition due to the excessive precipitation of chromium containing phases and carbides. Thus, the crack initiation and propagation were enhanced by an oxidation process. This has also been observed by [14, 21, 22, and in Fig. 7 this can be seen for the pre-aged specimen tested using $\Delta \varepsilon_{\text {mech }}=0.6 \%$. The oxidation process were most active during the dwell times, where the initiated crack tips had time to oxidise, thus adding to the embrittlement of the grain boundaries and then during the compressive part of the TMF-cycle, the brittle grain boundary oxides crack and then the process start over again. At half-life, the preaged specimens also show higher plastic strain amplitudes (Fig. 4b) and this should be connected to loss in solid solution strengthening during ageing. Elements forming solid solution precipitates like carbon $(\mathrm{Nb}(\mathrm{N}, \mathrm{C})$ and carbides), nitrogen $(\mathrm{Nb}(\mathrm{N}, \mathrm{C}))$ and tungsten (laves phase) are tied up due to excessive precipitation. Consequently, less dislocation movement can be impeded which gives increased plastic deformation. This has been studied in more detail by Heczko et al. and Polák et al. [15, 16, 22]. The strain rates during the dwell times, Fig. 4b, are in general also higher for the pre-aged specimens, which indicates that the change and raised levels of grain boundary precipitations also lowers the creep resistance. For the pre-aged specimens, the described higher ongoing plastic deformation yield a more steady state hardening behaviour (Fig. 3) until the deformation in the grains reaches its limit and the deformation are accommodated in the embrittled grain boundaries, which require higher stress. Large cracks forms when the stress is high enough to induce further deformation and propagate in the preferred damaged sites of the grain boundaries.

In Fig. 3a and Fig. 9a, the stress drops quickly after the maximum peak stress has been reached for virgin Sanicro 25 and virgin Sanicro 31HT tests with higher mechanical strain ranges. These drops are too small to render the specimens as "failed" according the limit suggested by [10. However, after the initial hardening, multiple surface crack initiations lowers the load-bearing area which results in continuously decreasing stress amplitude and when the small crack initiations coalesce, larger cracks are initiated which generate these sudden drops in stress 32. One example of this can be seen for a virgin Sanicro 25 specimen in Fig. 6a.

The resulting hardening/softening curves for Sanicro $31 \mathrm{HT}$ show similar characteristics as for the Sanicro 25 specimens, but at lower overall stress amplitudes. However, the overall stress amplitudes for the pre-aged specimens are lower than for the virgin specimens (Fig. 9). There is also a bigger difference in plastic strain amplitudes at half-life between two testing conditions of corresponding mechanical strain ranges, compared to the specimens of Sanicro 25. Besides, during the dwell time, the pre-aged specimens show higher strain rates compared to the virgin specimens at the same stress levels. All this indicates the detrimental influence of ageing on the mechanical prop- 
erties during thermomechanical fatigue. The microstructural differences of virgin and pre-aged Sanicro 31HT are showed in Fig. 15 and Fig. 17. From the images and the results presented in the previous section, it is clear that chromium carbides in the grain boundaries grows with increased ageing time and this have also been observed by other investigations [27, 28. The coarsening of these precipitates negatively affect the creep properties and relates to the increased strain rate during the dwell time for the pre-aged specimens [27]. The lowering in stress, needed for the mechanical straining, during TMF-cycling of the pre-aged specimens should be attributed to a decrease in solid solution strengthening due to the decrease of homogeneously distributed solid solution elements in the matrix. The decrease is probably related to increased amount and sizes of the titanium carbides and the carbides (both in the matrix and in the grain boundaries) that tie up the homogeneously distributed elements. This should give lower initial protection against the retardation of dislocation movement for the pre-aged specimens. When the deformation reaches a certain level inside the grains the stress levels must be high enough to start the damage process in the embrittled grain boundaries, thus giving the raise in stress before brittle failure along the grain boundaries occurs. This also relates to the difference in crack propagation between the virgin and pre-aged materials seen in Fig. 12 , where virgin condition experience more crack branching and secondary cracking compared to the pre-aged condition, for which the propagation is concentrated in a single crack front movement through grain boundaries.

The Esshete 1250 virgin and pre-aged specimens have the same principal differences in mechanical behaviour as for Sanicro 31HT. However, the softening of the Esshete 1250 virgin specimens starts already after 10 cycles and the different mechanical strain levels are reached with lower stress amplitudes, see Fig. 13a In addition, TMF testing for the pre-aged specimens could not be performed with mechanical strain ranges above $0.4 \%$ without fast failure and structural instabilities. An indication of this is the clear differences in the degree of deformation seen in Fig. 17 and between Fig. 15 and Fig. 16. The negative effect of ageing should be due to the presence of the big, condensed and less dispersed $\mathrm{Nb}$ - and C-rich precipitates (denoted type-1 sites) and the presence of accompanied C-, Cr- and Mo-rich precipitates (denoted type-4 sites) in Fig. 16, which depletes these elements in the matrix so that the amount of finely dispersed $\mathrm{NbC}$, Mo and $\mathrm{C}$ decreases substantially, thus lowering the creep resistance and the solid solution strengthening. The effect of depletion and coarsening of the NbC precipitates, have also been assessed by Yuin et al. 29]. This would explain the big differences in strain rate for relatively low stress levels during the dwell time for the virgin and pre-aged Esshete 1250. Moreover, the crack initiation and propagation seems to be oxidation assisted according to the microstructural images and the quantitative data, especially for the pre-aged condition. In this case the areas around the crack tips can be chromium depleted to critical levels due to the presence of the precipitates in type- 4 sites, this coincide with the brittle intergranular fracture seen in Fig. 17b. The same damaging cyclic oxidation process that was discussed for Sanicro 25, also apply for Esshete 1250.

\section{Conclusions}

The thermomechanical fatigue behaviour of three austenitic stainless steels were analysed. The influence of prolonged service degradation was simulated by pre-ageing of some specimens before TMF testing. The mechanical results were analysed and processed, yielding standard fatigue curves and coefficients. The SEM techniques EBSD, EDS and WDS were used to investigate and analyse the microstructure after testing, in order to understand the mechanical behaviour of the alloys during TMF testing. From this study, these conclusions were reached:

- All the materials investigated experienced a detrimental effect by the influence of pre-ageing. This was due to the decrease in both creep- and fatigue strength, attributed to negative microstructural evolution during the high temperature cyclic condition.

- For Sanicro 25 and Esshete 1250 the crack initiation and propagation was oxidation assisted, which added to the embrittling effect of the grain boundaries together with the precipitation of carbides. This leads to fast fracture for most of the pre-aged specimens.

- Of the investigated materials, Sanicro 25 showed the best thermomechanical fatigue performance, for both testing conditions. This was due to the superior microstructural strengthening mechanisms during high temperature conditions.

\section{Acknowledgements}

The present study was financially supported by $\mathrm{AB}$ Sandvik Materials Technology in Sweden and the Swedish Energy Agency through the Research Consortium of Materials Technology for Thermal Energy Processes, Grant No. KME-701.

\section{References}

[1] World Energy Council, World Energy Resources 2013, Tech. rep., World Energy Council, London (2013). URL https://www.worldenergy.org/publications/2013/ world-energy-resources-2013-survey/

[2] L. Trygg, S. Amiri, European perspective on absorption cooling in a combined heat and power system - A case study of energy utility and industries in Sweden, Appl. Energy 84 (12) (2007) 1319-1337. doi:10.1016/j.apenergy.2006.09.016.

[3] J. YIN, Z. WU, Corrosion Behavior of TP316L of Superheater in Biomass Boiler with Simulated Atmosphere and Deposit, Chinese J. Chem. Eng. 17 (5) (2009) 849-853. doi:10.1016/ S1004-9541(08)60286-4. 
[4] R. Viswanathan, K. Coleman, U. Rao, Materials for ultrasupercritical coal-fired power plant boilers, Int. J. Press. Vessel. Pip. 83 (11-12) (2006) 778-783. doi:10.1016/j.ijpvp. 2006. 08.006

[5] K. Dietrich, J. M. Latorre, L. Olmos, A. Ramos, The Role of Flexible Demands in Smart Energy Systems, in: Energy Syst., Springer, 2013, Ch. Optimizati, pp. 79-97. doi:10.1007/ 978-3-642-38134-8_4

[6] P. Viklund, A. Hjörnhede, P. Henderson, A. Stålenheim, R. Pettersson, Corrosion of superheater materials in a waste-to-energy plant, Fuel Process. Technol. 105 (2013) 106-112. doi:10.1016/ j.fuproc.2011.06.017

[7] T. Sourmail, Precipitation in creep resistant austenitic stainless steels, Mater. Sci. Technol. 17 (January) (2001) 1-14. doi: 10.1179/026708301101508972

[8] Sandvik, Sanicro 25 Tube and Pipe, Seamless Datasheet (2008). URL https://www . materials . sandvik/en/materials-center/ material-datasheets/

[9] R. Hormozi, F. Biglari, K. Nikbin, Experimental study of type 316 stainless steel failure under LCF/TMF loading conditions, Int. J. Fatigue 75 (2015) 153-169. doi:10.1016/j.ijfatigue. 2015.02.014

[10] P. Hähner, E. Affeldt, T. Beck, H. Klingelhöffer, M. Loveday, C. Rinaldi, Final version of the Validated Code-of-Practice for Thermo-Mechanical Fatigue Testing, Tech. Rep. June, European Comission: Directorate-General Joint Research Centre (DG JRC) and Institute for energy, Petten (Netherlands) (2006).

URL https://netzwerke.bam.de/Netzwerke/Content/EN/ Downloads/jrc-tmf-validated-code-of-practice.pdf? blob=publicationFile

[11] H. Wärner, M. Calmunger, G. Chai, J. Polák, R. Petráš, M. Heczko, T. Kruml, S. Johansson, J. Moverare, Fracture and Damage Behavior in an Advanced Heat Resistant Austenitic Stainless Steel During LCF , TMF and CF, Procedia Struct. Integr. 13 (2018) 1-6.

[12] G. Golański, A. Zieliński, H. Purzyńska, Precipitation Processes in Creep-Resistant Austenitic Steels, in: Austenitic Stainl. Steels - New Asp., InTech, 2017. doi:10.5772/intechopen. 70941

[13] P. Liu, Phase analysis in steel using analytical transmission electron microscopy, 1st Edition, Sandvik AB, Sandviken, 2004.

[14] V. Mazánová, M. Heczko, J. Polák, Fatigue crack initiation and growth in $43 \mathrm{Fe}-25 \mathrm{Ni}-22.5 \mathrm{Cr}$ austenitic steel at a temperature of $700{ }^{\circ} \mathrm{C}$, Int. J. Fatigue 114 (114) (2018) 11-21. doi:10.1016/ j.ijfatigue.2018.04.033

[15] M. Heczko, B. D. Esser, T. M. Smith, P. Beran, V. Mazánová, D. W. McComb, T. Kruml, J. Polák, M. J. Mills, Atomic resolution characterization of strengthening nanoparticles in a new high-temperature-capable $43 \mathrm{Fe}-25 \mathrm{Ni}-22.5 \mathrm{Cr}$ austenitic stainless steel, Mater. Sci. Eng. A 719 (December 2017) (2018) 49-60. doi:10.1016/j.msea.2018.02.004

[16] M. Heczko, J. Polák, T. Kruml, Microstructure and dislocation arrangements in Sanicro 25 steel fatigued at ambient and elevated temperatures, Mater. Sci. Eng. A 680 (October 2016) (2017) 168-181. doi:10.1016/j.msea.2016.10.076.

[17] J. Zurek, S.-M. Yang, D.-Y. Lin, T. Hüttel, L. Singheiser, W. J. Quadakkers, Microstructural stability and oxidation behavior of Sanicro 25 during long-term steam exposure in the temperature range 600-750 ${ }^{\circ} \mathrm{C}$, Mater. Corros. 66 (4) (2015) 315-327. doi: $10.1002 / \mathrm{maco} .201407901$

[18] S. Vujic, M. Farooq, B. Sonderegger, R. Sandström, C. Sommitsch, Numerical modelling and validation of precipitation kintecs in advanced creep resistent austenitic steel, Calphad 12 (4) (2012) 225-232.

[19] B. Sundman, B. Jansson, J. O. Andersson, The Thermo-Calc databank system, Calphad 9 (2) (1985) 153-190. doi:10.1016/ 0364-5916(85) 90021-5

[20] G. Chai, M. Boström, M. Olaison, U. Forsberg, Creep and LCF behaviors of newly developed advanced heat resistant austenitic stainless steel for A-USC, Procedia Eng. 55 (2013) 232-239. doi:10.1016/j.proeng.2013.03.248

[21] R. Petráš, J. Polák, Damage mechanism in austenitic steel during high temperature cyclic loading with dwells, Int. J. Fatigue 113 (2018) 335-344. doi:10.1016/j.ijfatigue. 2018.02.017

[22] J. Polák, R. Petráš, M. Heczko, I. Kuběna, T. Kruml, G. Chai, Low cycle fatigue behavior of Sanicro25 steel at room and at elevated temperature, Mater. Sci. Eng. A 615 (2014) 175-182. doi:10.1016/j.msea.2014.07.075

[23] J. Polák, R. Petráš, M. Heczko, T. Kruml, G. Chai, Evolution of the cyclic plastic response of Sanicro 25 steel cycled at ambient and elevated temperatures, Int. J. Fatigue 83 (2015) 75-83. doi : 10.1016/j.ijfatigue.2015.03.015

[24] R. Petráš, V. Skorík, J. Polák, Thermomechanical fatigue and damage mechanisms in Sanicro 25 steel, Mater. Sci. Eng. A 650 (2016) 52-62. doi:10.1016/j.msea.2015.10.030

[25] L. Tan, L. Rakotojaona, T. Allen, R. Nanstad, J. Busby, Microstructure optimization of austenitic Alloy $800 \mathrm{H}$ (Fe-21Cr-32Ni), Mater. Sci. Eng. A 528 (6) (2011) 27552761. doi:10.1016/j.msea.2010.12.052

[26] E. El-Magd, G. Nicolini, M. Farag, Effect of carbide precipitation on the creep behavior of Alloy $800 \mathrm{HT}$ in the Temperature Range $700{ }^{\circ} \mathrm{C}$ to $900{ }^{\circ} \mathrm{C}$, Metall. Mater. Trans. A 27 (3) (1996) 747-756. doi:10.1007/BF02648962

[27] Z. Khan, F. Al-Habib, N. Merah, I. Allam, The effect of thermal ageing on the microstructure and fatigue strength of alloy 800HT, Int. J. Microstruct. Mater. Prop. 3 (4-5) (2008) 616629.

[28] J. Erneman, J.-O. Nilsson, H.-O. Andrén, D. Tobjörk, Microstructural Evolution during Creep of Alloy $800 \mathrm{HT}$ in the Temperature Range $600{ }^{\circ} \mathrm{C}$ to $1000{ }^{\circ} \mathrm{C}$, Metall. Mater. Trans. A 40 (3) (2009) 539-550. doi:10.1007/s11661-008-9751-7

[29] C. Yuin, Microstructure Evolution in Nb Alloyed Esshete 1250 Creep Resistant Austenitic Stainless Steel, Ph.D. thesis (2008).

[30] C. Mapelli, P. Nolli, Formation Mechanism of Non-Metallic Inclusions in Different Stainless Steel Grades, ISIJ Int. 43 (8) (2003) 1191-1199. doi:10.2355/isijinternational.43.1191

[31] S. Osgerby, a. T. Fry, Steam Oxidation Resistance of Selected Austenitic Steels, Mater. Sci. Forum 461-464 (2004) 1023-1030. doi:10.4028/www.scientific.net/MSF.461-464.1023

[32] U. Lindstedt, B. Karlsson, M. Nyström, Small Fatigue Cracks In An Austenitic Stainless Steel, Fatigue Fract. Eng. Mater. Struct. 21 (1998) 85-98. 